\title{
Long-Lasting Reconfiguration of Two Interacting Networks by a Cooperation of Presynaptic and Postsynaptic Plasticity
}

\author{
Romuald Nargeot \\ Université Bordeaux 1, Centre National de la Recherche Scientifique Unité Mixte de Recherche 5816, Laboratoire de \\ Neurobiologie des Réseaux Bâtiment Biologie Animale, 33405 Talence Cedex, France
}

The functional reconfiguration of central neuronal networks, a phenomenon by which neurons change their participation in network operation, is important for organizing adaptive behaviors. Such reconfiguration can be expressed in a long-lasting manner (hours, days) after a training paradigm. The present study shows that such a long-lasting network reconfiguration requires a cooperation of both presynaptic and postsynaptic modifications in a neuronal interaction between two functionally distinct networks. In isolated preparations of the lobster stomatogastric nervous system, the single ventral dilator (VD) neuron can switch its functional participation from one discrete network (the pyloric network) to another (the cardiac sac network). This switching capability can be long-lasting and can be induced by a sensitizing procedure. A persistent change that was associated with this neuronal switching was found in each of the two networks. First, the intrinsic membrane properties of the VD neuron that allow it to participate spontaneously in the pyloric network are altered. Second, bursting activity is strengthened in the inferior ventricular neurons that both drive cardiac sac network activity and monosynaptically excite the VD neuron in phase with this network activity. Importantly, these changes in intrinsic properties of both presynaptic and postsynaptic neurons are required to allow the VD neuron switching, because expression of either the presynaptic or the postsynaptic change alone did not permit VD neuron switching to occur. These results suggest that a cooperative modification of a discrete network interaction is able to persistently switch the output pattern of a motor neuron as a result of a sensitizing paradigm.

Key words: lobster stomatogastric nervous system; central pattern generator; network reconfiguration; motor pattern switching; membrane properties; plasticity; neuronal cooperation
Central neuronal networks are assemblies of neurons that serve a specific biological function. It is now apparent that these networks are not fixed structures, but rather, they are dynamic assemblages in which neurons may change their functional state to alter their contribution to network operation (Pearson et al., 1987; Clark et al., 1988; Hooper and Moulins, 1989; Dickinson et al., 1990; Meyrand et al., 1991; Wu et al., 1994; Nargeot et al., 1999a,b). Such dynamic processes underlie functional reconfigurations of neuronal networks that contribute to sensory processing and genesis of behaviors (Singer, 1990; Dickinson, 1995; Edeline, 1998). In several cases, network reconfigurations are induced in a persistent manner (lasting hours, days) by training procedures (Jenkins et al., 1990; Kleim et al., 1998; Nargeot et al., 1999a,b). However, the mechanisms involved in such long-lasting circuit reconfigurations are still poorly understood.

The study of central neuronal networks that generate rhythmic behaviors [i.e., central pattern generators (CPGs)] may help to address this issue. Several CPGs have been described in terms of their synaptic organization, intrinsic membrane properties, and modulatory and sensory inputs (Rossignol and Dubuc, 1994;

Received Nov. 29, 2000; revised Feb. 14, 2001; accepted Feb. 22, 2001.

I thank Dr. P. Meyrand for helpful readings and comments on earlier drafts of this manuscript and Drs. J. H. Byrne, H. A. Lechner, and J. Simmers for reviewing this manuscript.

Correspondence should be addressed to Dr. Romuald Nargeot, Université Bordeaux 1, Centre National de la Recherche Scientifique Unité Mixte de Recherche 5816, Laboratoire de Neurobiologie des Réseaux Bâtiment Biologie Animale B2, Avenue des Facultés, 33405 Talence Cedex, France. E-mail: r.nargeot@Inr.u-bordeaux.fr.

Copyright (C) 2001 Society for Neuroscience $0270-6474 / 01 / 213282-13 \$ 15.00 / 0$
Bianchi et al., 1995; Marder and Calabrese, 1996; Baxter et al., 1997; Benjamin et al., 2000), and several of these inputs induce long-lasting CPG reconfigurations (Nargeot and Moulins, 1997; Le Feuvre et al., 1999; Nargeot et al., 1999a,b).

In this context, a suitable model for studying the mechanistic basis of such training-induced network reconfigurations are the CPG circuits of the lobster stomatogastric nervous system. The pyloric and the cardiac sac CPG networks that mediate rhythmic movements of the pyloric chamber and the cardiac sac of the foregut, respectively, have been well characterized (Selverston and Moulins, 1987; Harris-Warrick et al., 1992) (see Fig. 14A). Moreover, in in vitro preparations, a simple form of functional reconfiguration involving both these networks has been described. Stimulation of a mechanosensory input nerve from the foregut transiently (tens of seconds) suppresses participation of the ventral dilator (VD) neuron in the pyloric network and makes this cell active with the cardiac sac network (Hooper and Moulins, 1989). Two transient effects are implicated in this switching. First, a modulatory effect that inactivates intrinsic pyloric-timed bursting in the VD cell thereby effectively eliminates this neuron from the pyloric network. Second, a 1-2 sec burst of action potentials is elicited in the VD neuron by a synaptic drive from the pattern generating inferior ventricular (IV) cells of the cardiac sac network, thereby rendering the VD neuron active with this network. Moreover, long-lasting (i.e., hours) changes are induced by a sensitizing stimulation of the contralateral mechanosensory nerve, which enhances this capability for the VD neuron to switch from the pyloric to the cardiac sac pattern (Nargeot and Moulins, 1997). The present study shows that 



Figure 1. Neuronal responses to a single stimulation of vpln. A, Schematic representation of the in vitro stomatogastric nervous system showing the position of the stimulating ( filled arrowhead) electrodes on the mechanosensory nerves (vpln) and intracellular recording (unfilled arrowhead) electrodes in IV, VD, and PD neurons. $B$, When the cardiac sac network (as monitored in IV) is not rhythmically active, the pyloric network spontaneously generates a fast $(\sim 1 \mathrm{~Hz})$ rhythmic output as monitored in PD and VD neurons (before stimulation). A vpln stimulation (40 Hz, $1 \mathrm{sec}$; horizontal bar marked vpln Stim) activates the cardiac sac network and briefly perturbs PD neuron activity during the cardiac sac burst (IV neuron spike burst). In the VD neuron, the stimulation always elicits both a burst of spikes during the cardiac sac activity and a short-lasting inactivation of pyloric firing. Inactivation duration was measured from the beginning of the stimulation to the recovery of the first action potential occurring during a pyloric-time VD neuron oscillation. Calibration: $10 \mathrm{mV}$. CoG, Commissural ganglion; $I V$, inferior ventricular neuron; $O G$, esophageal ganglion; $P D$, pyloric dilator neuron; Sens Stim, sensitizing stimulation; STG, stomatogastric ganglion; VD, ventricular dilator neuron; conn., supraesophageal-commissural connective; ion, inferior esophageal nerve; ivn, inferior ventricular nerve; son, superior esophageal nerve; stn, stomatogastric nerve; $v p l n$, ventral posterolateral sensory nerve.

changes in membrane properties of the postsynaptic VD neuron and in firing properties of the presynaptic IV cells are associated with this long-lasting neuronal switching. Furthermore, the switching is expressed only when plasticity occurs conjointly in both these presynaptic and postsynaptic elements of a connection between the two different networks.

Some of the results have been published previously in abstract form (Nargeot, 2000).

\section{MATERIALS AND METHODS}

Spiny lobsters (Palinurus vulgaris) were obtained from Primel (Plougasnou, Bretagne, France) and maintained in circulating and aerated seawater until used. Stomatogastric nervous systems were isolated from the animals and pinned out in a Sylgard-coated Petri dish. This in vitro preparation comprised the stomatogastric ganglion (STG), the two commissural ganglia (CoG), the esophageal ganglion (OG), and their interconnecting nerves (Fig. 1A). The supraesophageal ganglion was removed from the preparation, except for a ventral segment of tissue that was left attached to the esophageal ganglion by the inferior ventricular nerve (ivn) (Claiborne and Selverston, 1984). This preparation also contained the motor nerves from the STG and the bilateral ventral-posterolateral mechanosensory nerve (vpln), which enters the CoG. Preparations were perfused during the experiments with saline composed of (in $\mathrm{mM}$ ): $\mathrm{NaCl}$ 479.12, $\mathrm{KCl} 12.74, \mathrm{CaCl}_{2}-2 \mathrm{H}_{2} \mathrm{O}$ 13.67, $\mathrm{MgSO}_{4} 10, \mathrm{Na}_{2} \mathrm{SO}_{4}$ 3.91, and HEPES $5, \mathrm{pH} 7.45$, and were maintained at $15^{\circ} \mathrm{C}$ by means of a Peltier cooling device.

Electrophysiology. Extracellular recordings were made using monopolar wire electrodes placed against selected peripheral nerves. To stimulate nerves, currents were generated by a Grass S 88 stimulator and were applied through a photoisolation unit to bipolar wire electrodes. Electrodes for extracellular stimulation and recording were isolated from the bath with petroleum jelly (Vaseline). Training and control stimulation paradigms were identical to those described earlier (Nargeot and Moulins, 1997). Briefly, in the training paradigm, an initial series of repetitive vpln stimulations was used to select preparations that expressed a constant VD inactivation duration. The 10-12 stimulations in this series were composed of $0.5 \mathrm{msec}$ pulses at $40 \mathrm{~Hz}$ for $1 \mathrm{sec}$ with a magnitude of $5 \mathrm{~V}$ and were delivered for $5.5 \mathrm{~min}$ at intervals of $30 \mathrm{sec}$. Subsequently, a sensitizing stimulation was applied to the contralateral vpln. This sensitizing stimulation was composed of a series of 46 stimulations each composed of $0.5 \mathrm{msec}$ pulses at $40 \mathrm{~Hz}$ for $1 \mathrm{sec}$ with a magnitude ( $\geq 8 \mathrm{~V}$ ) eliciting maximal response in the VD neuron and were delivered for 45 min at $1 \mathrm{~min}$ interval. The effects of this sensitizing stimulation were subsequently tested by a series of stimuli identical to the initial one. The control paradigm differed from the training paradigm only by the absence of the sensitizing stimulation.

Intracellular recordings were made with glass microelectrodes filled with $3 \mathrm{M} \mathrm{KCl}$ or $\mathrm{KCH}_{3} \mathrm{CO}_{2}$ (resistance 10-20 M 2 ) and implanted in neuronal somata. Signals were amplified by electrometers (S7071, World Precision Instruments; Axoclamp-2A, Axon Intruments, Union City, CA) and visualized on an oscilloscope (Tecktronix 5113) and an electrostatic recorder (Gould, ES 1000). Signals were stored on videotape or CD-ROM after digitization by an analog-to-digital converter (Neurodata, DR-886 or Cambridge Electronic Design, CED 1401).

Two electrode current-clamp technique was used to test input resistance of the VD neuron. In this procedure, VD membrane potential was held at $-65 \mathrm{mV}$ by constant intracellular current injection after the neuron was isolated in situ from the pyloric network (see below). Input resistance was calculated by the difference between the membrane potential of the VD neuron before and at the termination of an additional brief $(500 \mathrm{msec})$ hyperpolarizing current pulse. Data were normalized to the mean VD neuron response recorded during an initial series of five negative current pulses.

Identification, stimulation, and in situ photoinactivation of IV neurons. The IV axons are the only fibers in the ivn that project through the stn to the STG (Fig. 1A) (Moulins and Vedel, 1977). Action potentials in the IV neurons elicit time-locked EPSPs in the VD neuron, suggesting a monosynaptic connectivity (Moulins and Vedel, 1977; Hooper and Moulins, 1990). Using these criteria, the IV cell bodies were identified on the inside surface of the basal connective tissue of the supraesophageal ganglion, a position similar to the IV somata location in the related species, Palinurus interruptus (Claiborne and Selverston, 1984).

IV neuron firing was induced by intracellular injection of depolarizing current pulses or, when the cell bodies were not found or could not be trigger intracellularly, by extracellular stimulation $(0.5 \mathrm{msec}, 5 \mathrm{~V}$ pulses $)$ of the IV axons in the ivn. The frequency and duration of the elicited activity in the IV neurons were set manually or through an automated procedure. When set manually, the IV neurons were stimulated at $55 \mathrm{~Hz}$ for 1-2.3 sec. With intracellular stimulation, a depolarizing current pulse $(100-200 \mathrm{msec})$ was set in intensity to trigger a single IV neuron action potential. This pulse was delivered repetitively at the previously indicated frequency and duration. In the automated procedure, IV neuron stimulation in a given preparation (the "target" preparation) was triggered by the IV neuron action potentials recorded in another preparation (the "source" preparation). The "target" IV neuron was stimulated by a depolarizing current pulse (see above) generated by the Grass stimulator and triggered by a custom made window discriminator set to detect recorded action potentials of the "source" IV neuron. The trigger threshold of the window discriminator was set at a potential ranging between the IV neuron resting membrane potential and the maximal amplitude of 
the smallest IV neuron spike of the source preparation. By this method, action potentials recorded in the IV neuron of the source preparation could be replicated with a one-for-one relationship with IV neuron spikes of the target preparation.

In situ photoinactivation of IV neuron axons was done both by cutting the ivn, thereby disconnecting the IV somata, and by photoinactivating the IV neuron axonal projections in the remaining preparation. Photoinactivation was done after a $24 \mathrm{hr}$ anterograde migration of Lucifer yellow (Sigma, St. Louis, MO; $3 \%$ in distilled water) through the ivn and by subsequent illumination of the preparations with blue light (450-490 $\mathrm{nm}, 100 \mathrm{~W}$ mercury lamp). Illumination was focused on the son/on/stn junction, where only the IV fibers are labeled.

Synaptic blockade and in situ cell isolation. Blockade of synaptic transmission was made using artificial seawater containing $\mathrm{Co}^{2+}$ and a low $\mathrm{Ca}^{2+}$ concentration (in $\mathrm{mm}$ ): $\mathrm{NaCl} 436.2, \mathrm{KCl} 9.79, \mathrm{CaCl}_{2} 3, \mathrm{MgCl}_{2}$ 59.63, $\mathrm{NaHCO}_{3} 2.5$, and $\mathrm{CoCl}_{2} 10, \mathrm{pH} 7.45$. The solution was perfused in a Vaseline chamber surrounding the desheathed OG.

In situ synaptic isolation of the VD neuron from its pyloric network partners was performed by photoinactivation of the presynaptic cholinergic pyloric dilator (PD) and anterior burster (AB) neurons [the method of photoinactivation is described in Miller and Selverston $(1979,1982)$ and Bal et al. (1988)] and by blockade of the remaining glutamatergic synapses with picrotoxin $\left(5 \times 10^{-5} \mathrm{M}\right)$ perfused on the STG (Bidaut, 1980). In some experiments (e.g., Fig. 6B), VD neuron isolation was performed in preparations in which the CoGs had been removed and synaptic activity in the OG was suppressed. In these preparations, VD neuron oscillatory properties were induced pharmacologically by perfusion of oxotremorine (Sigma; $10^{-5}$ M) on the STG (Bal et al., 1994).

Data analysis. Preparations used in the present study were preselected on the basis of VD neuron activity levels. In all preparations, the VD neuron spontaneously expressed a pyloric pattern while the cardiac sac network was silent or expressed erratic spiking activity (Hooper and Moulins, 1989; Hooper et al., 1990). Phasic $(40 \mathrm{~Hz}, 1 \mathrm{sec})$ stimulation of a vpln inactivated VD neuron pyloric activity (Fig. $1 B$ ) (Hooper et al., 1990). The duration of this inactivation was measured from the beginning of the stimulation to the time of the first VD neuron action potential occurring during a poststimulus pyloric VD neuron oscillation (Nargeot and Moulins, 1997). Recovery interval can vary with repeated vpln stimulation (Fig. 2B). Preparations were classified as expressing constant inactivation duration when the slope of the linear regression of successive inactivation duration (calculated from at least eight stimulations) was within the interval of \pm 0.4 . They were classified as expressing an increasing inactivation duration when the slope of the linear regression was $>0.4$ and a decreasing inactivation duration when the slope of the linear regression was less than -0.4 . Preparations $(21 \%)$ expressing a decreasing inactivation duration during the initial stimulation series were not analyzed in the present study. A single spontaneous burst of cardiac sac activity (i.e., $\geq 10$ spikes at $\geq 6 \mathrm{~Hz}$ in the IV neurons or IV neuronderived EPSPs recorded in the VD neuron) may occur during the VD neuron inactivation elicited by vpln stimulation. In such cases, the duration of the VD neuron inactivation induced by the spontaneous IV neuron activity was excluded from the data. Isolated spikes associated with cardiac sac activity (i.e., a spiking IV neuron or VD neuron EPSPs of $<6 \mathrm{~Hz}$ ) were neglected when quantifying IV or VD neuron response durations. Finally, preparations $(7 \%)$ were excluded when VD neuron inactivation duration in response to the first vpln stimulation in a series was more than the $30 \mathrm{sec}$ interstimulus interval (Nargeot and Moulins, 1997).

Parts of the data were analyzed off-line using a Spike2 software (Cambridge Electronic Design). Statistical comparisons were made using a two-tailed paired $t$ test $(t)$ and factorial ANOVA $(F)$. ANOVA with repeated measures was used in a paired-samples procedure. In some experiments, three factors (stimulation of vpln, series of stimulation of vpln, and sensitizing stimulation) were tested. Data from such experiments were analyzed using both a one-factor ANOVA with repeated measures to test the effect of the successive vpln stimulation in a single series and a two-factor ANOVA with repeated measures to test the effects of the two remaining factors. In two-factor ANOVA, the $F$ values indicated in the text and figures refer to the interaction between the factors. Post hoc pairwise multiple comparisons were made using the Newman-Keuls test $(q)$. For all tests, probabilities $(p$ values $)<0.05$ were considered statistically significant.
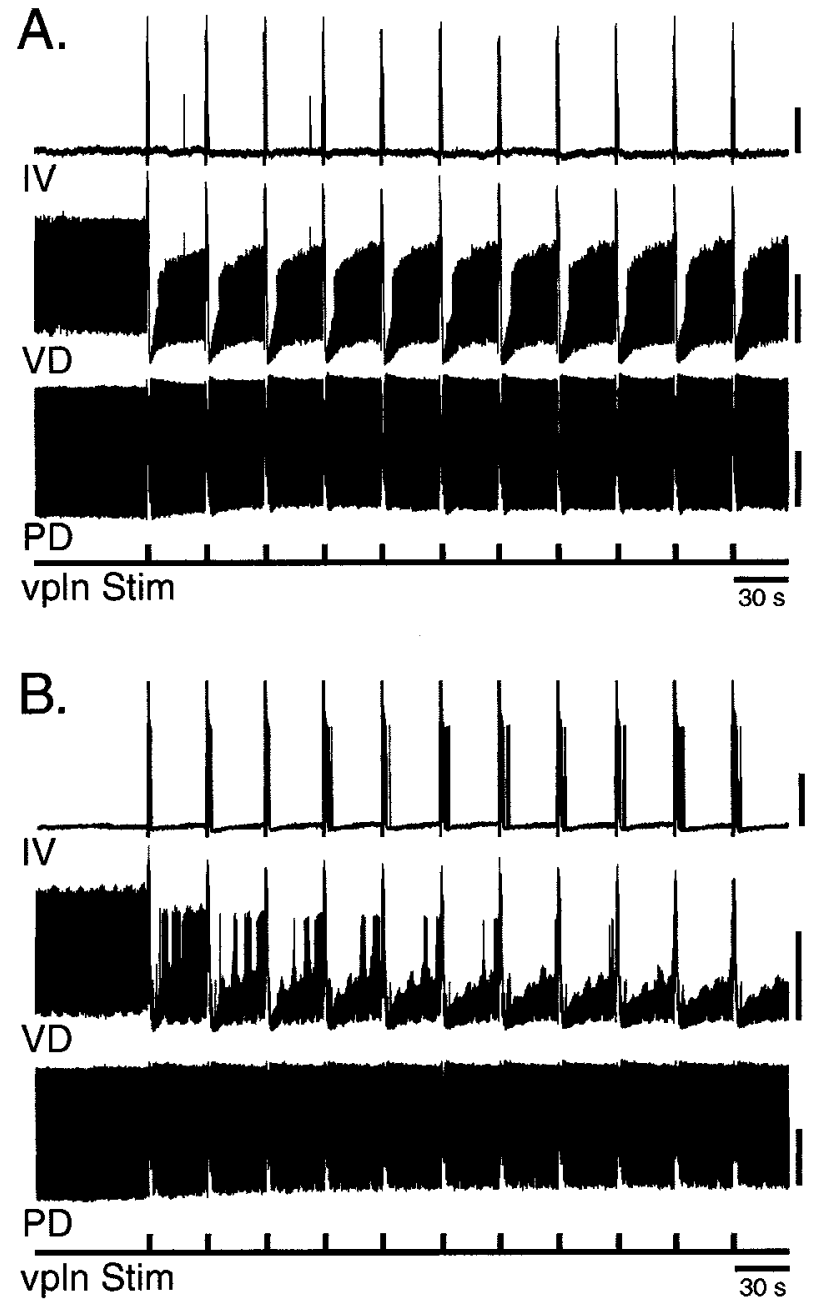

Figure 2. VD neuron switching elicited by rhythmic vpln stimulation. Two preparations $(A, B)$ in which the VD neuron originally expressed pyloric network activity (compare with PD neurons; note different timescale with Fig. 1). Rhythmic cardiac sac network activity (IV neuron trace) was elicited by rhythmic vpln stimulation (vertical bars in vpln Stim, $40 \mathrm{~Hz}$ for $1 \mathrm{sec}$ every $30 \mathrm{sec}$ ). VD neuron inactivation duration either remained unchanged with stimulus repetition $(A)$ or progressively increased $(B)$. In the latter case, the VD neuron progressively lost its capability to fire with the pyloric network (compare VD and PD neurons activity after the last stimulation) and became only active with the cardiac sac network (compare VD and IV neuron activities). Thus, in some preparations VD neuron activity progressively switched from the pyloric to the cardiac sac pattern. Calibration: $10 \mathrm{mV}$.

\section{RESULTS}

\section{VD neuron switching induced by a} sensitizing stimulation

The pyloric network spontaneously generates a rhythmic motor pattern with a characteristic frequency of $\sim 1 \mathrm{~Hz}$ (Fig. $1 B$, before vpln stimulation). The timing of this rhythmic activity is determined by the $\mathrm{PD}-\mathrm{AB}$ pacemaker group (Selverston and Miller, 1980; Miller and Selverston, 1982; Eisen and Marder, 1984; Bal et al., 1988). The cardiac sac network is silent in $\sim 50 \%$ of preparations, but when spontaneously active, it produces a motor pattern characterized by rhythmic impulse bursts with a mean period of $\sim 30 \mathrm{sec}$ (Moulins and Vedel, 1977). This spontaneous cardiac sac activity that is expressed as a synchronous activity in different synaptically connected neurons is driven by the IV neurons (Claiborne and Selverston, 1984). The VD neuron can be active with 
either network. When the cardiac sac network is silent, the VD neuron is spontaneously active with the pyloric network (Fig. $1 B$, before vpln stimulation). When the cardiac sac network is active, the spontaneous pyloric firing of the VD neuron is inactivated by a transient modulator effect, and it now fires with the cardiac sac network (Hooper and Moulins, 1990).

The cardiac sac network and the modification of VD neuron firing can also be triggered by distention of the cardiac sac wall or electrical stimulation of the mechanosensory vpln arising from this wall (Hooper et al., 1990). A single vpln stimulation $(0.5 \mathrm{msec}$ pulses at $40 \mathrm{~Hz}$ for $1 \mathrm{sec}$ ) always elicits an impulse burst in the cardiac sac network, including the VD neuron, and a transient inactivation of the spontaneous pyloric firing of the VD neuron (Fig. 1B). Periodic (30 sec intervals) vpln stimulation produces the rhythmic cardiac sac activity associated with rhythmic impulse bursts in the VD neuron. This rhythmic vpln stimulation elicits in some preparations $(n=96)$ successive VD neuron inactivation of constant and short duration (several seconds) (Fig. $2 A)$. In other preparations $(n=22)$, the inactivation duration progressively increases (Fig. $2 B$ ) so that the VD neuron progressively loses its ability to rejoin the pyloric pattern, and hence gradually switches from being a mixed pyloric-cardiac sac circuit neuron to being a purely cardiac sac network element.

In preparations in which an initial series of rhythmic vpln stimulation did not cause the VD neuron pattern switching (Figs. $2 A, 3 C$, vpln stimulation 1-12), such a response can be experimentally induced by a sensitizing paradigm (Fig. 3; Nargeot and Moulins, 1997; see also Materials and Methods). The sensitizing paradigm that was applied in a trained group of preparations consisted of repetitive stimulation of the contralateral vpln and differed from the initial vpln stimulations by a larger number of stimulation (46), a longer period of delivery (45 min), and a larger pulse magnitude ( $\geq 8 \mathrm{~V}$ ) (Fig. $3 A$ ). In a control group of preparations, the corresponding training period consisted of a rest period with no stimulation (Fig. $3 B$ ). The first stimulation that was applied on the original vpln 40 min after the training periods did not show any change in VD neuron inactivation duration (Fig. $3 C$, vpln stimulation 13). However, this duration progressively increases when the vpln stimulation was repeated rhythmically in the trained group, but not the control group (Fig. 3C, compare VD neuron inactivation duration to stimulation $14-24$ to the response to stimulation $1-12$ and to the corresponding control values). Thus, a long-lasting effect that gradually increase VD neuron inactivation duration in response to rhythmic vpln stimulation was induced by the sensitizing stimulation.

This result is similar to that described earlier by Nargeot and Moulins (1997) and indicates that the sensitizing stimulation induces the capability for the VD neuron to switch persistently from the pyloric to the cardiac sac pattern. These preparations thereby provide an opportunity to analyze the cellular modifications associated with this long-lasting neuronal network switching. In a first step in this analysis, stimulus-evoked changes that may occur in the pyloric and the cardiac sac networks were investigated.

\section{Induced plasticity in VD neuron membrane properties}

The change in VD neuron inactivation after training could be associated with persistent modifications in intrinsic membrane properties of the neuron itself. To test this possibility, the spontaneous firing and membrane potential of the VD neuron were compared before and after training and with corresponding control group values. Spontaneous VD neuron firing was quantified

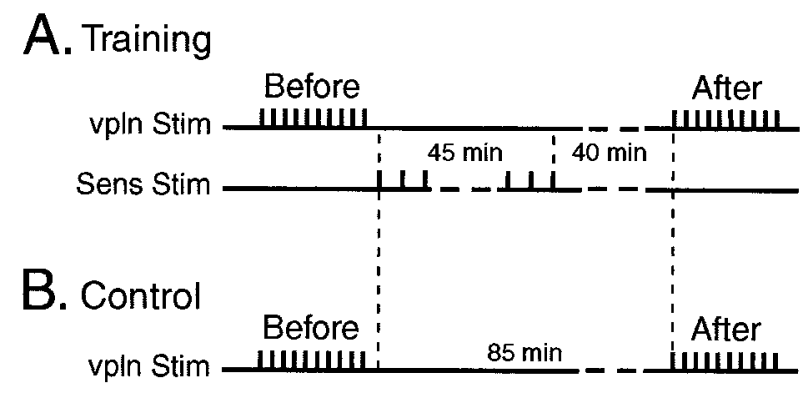

Sens Stim



Figure 3. Induction of motor pattern switching capability in the VD neuron. A stimulation paradigm was applied to a trained group and a control group of preparations ( $A$ and $B$, respectively) and was divided into three periods: pre-training, training, and test periods. In both groups, the pre-training period was composed of a first series of 10-12 vpln stimulations $(40 \mathrm{~Hz}$ for $1 \mathrm{sec}, 5 \mathrm{~V}$, with a $30 \mathrm{sec}$ period, see vertical bars in vpln Stim). This stimulation was used to select preparations that expressed a constant VD neuron inactivation duration. The training period lasted 45 min and was composed in the trained group of a series of sensitizing stimulation to the contralateral vpln $(40 \mathrm{~Hz}$ for $1 \mathrm{sec}$ every $1 \mathrm{~min}$ at intensity eliciting maximum VD neuronal response) and in the control group of a rest period (no stimulation applied) $(B)$. The test period began $40 \mathrm{~min}$ after the training period and was composed in both groups of a new series of vpln stimulation that was identical to the pre-training series. $C$, Comparison of VD neuron inactivation duration elicited by vpln stimulation in the trained (black circles; $n=10$ ) and the control (white circles; $n=10$ ) groups. This duration progressively and significantly increased in the trained group during the vpln stimulation in the test period, indicating that the sensitizing stimulation (arrow) induced the capability for network switching in the VD neuron $(F=6.223, p<0.025$; before vs after training in trained group, $\mathrm{q}_{2}=4.191, p<0.01$; in control group $\mathrm{q}_{2}=0.580$; between groups before training, $\mathrm{q}_{2}=0.790$; after training, $\mathrm{q}_{2}=2.915, p<0.05$; effect of repetition of vpln stimulation in trained group after training, $F=6.839, p<0.001$ ). Data in this and subsequent figures are expressed as mean \pm SEM.

as the mean number of action potentials generated in 10 successive bursts of spontaneous pyloric activity. Recording samples analyzed were immediately before the initial (i.e., pre-training) series of vpln stimulations and immediately before the posttraining series of vpln stimulations (i.e., 40 min after the training period). The number of spontaneous action potentials per VD neuron burst varied significantly between groups as a function of training (Fig. 4A,B). It decreased after the sensitizing stimulation compared with before or either of the control group values. Thus, 

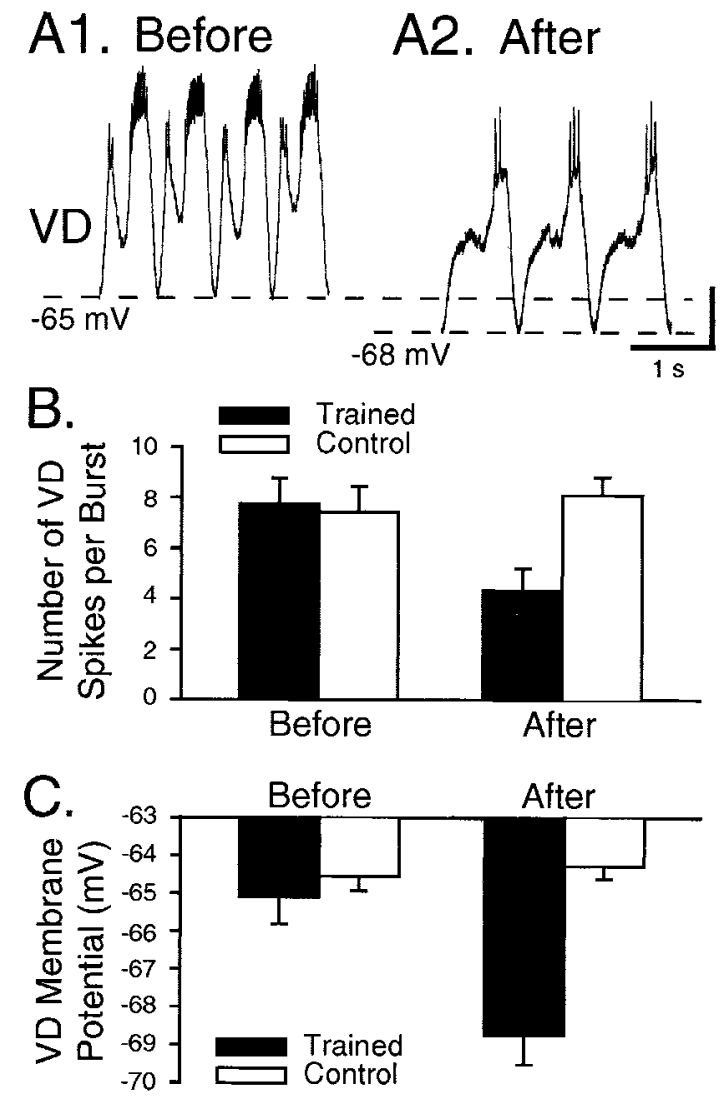

Figure 4. Decrease in spontaneous pyloric firing of the VD neuron. $A$, Recordings of spontaneous pyloric oscillatory activity in a VD neuron before $(A 1)$ and $40 \mathrm{~min}$ after $(A 2)$ sensitizing stimulation in a trained preparation. After training, the number of action potentials per VD neuron burst decreased as the cell hyperpolarized (dashed lines). Calibration: $5 \mathrm{mV}$. B, Mean number of spikes per VD neuron burst compared before and 40 min after sensitizing stimulation in the trained (black bars) and the control groups (white bars). The VD neuron fired significantly fewer spikes per burst after the sensitizing stimulation compared with before or with control values. Data are from the preparations described in Figure $3(F=9.021, p<0.01$; before vs after training in trained group: $\mathrm{q}_{2}=5.025, p<0.005$; in control group: $\mathrm{q}_{2}=0.982$; between groups before training: $\mathrm{q}_{2}=0.394$; after training: $\left.\mathrm{q}_{2}=4.648, p<0.005\right)$. $C$, Comparison of VD membrane potential recorded between bursts (see dashed lines in $A$ ) before and 40 min after sensitizing stimulation in the trained (black bars) and control groups (white bars) described in Figure 3. A significant hyperpolarization of the VD neuron was recorded after training compared with before training or with the control values, $F=15.466, p<$ 0.001 ; before vs after training in trained group, $\mathrm{q}_{2}=7.508, p<0.001$; in control group, $\mathrm{q}_{2}=0.544$; between groups before training, $\mathrm{q}_{2}=0.563$; after training, $\mathrm{q}_{2}=7.261, p<0.001$.

the sensitizing stimulation persistently $(>40 \mathrm{~min}$ ) weakened the ability of the VD neuron to spontaneously generate pyloric-timed action potentials.

The membrane potential level attained by the VD neuron between spontaneous pyloric bursts was also compared between groups, from the same burst sequences as described above. A sustained hyperpolarization of the VD neuron was observed after the sensitizing stimulation (Fig. 4A). This shift depended on training; it was not observed in the control group (Fig. $4 C$ ). Thus the training-induced decrease in the spontaneous pyloric firing of the VD neuron was associated with a hyperpolarization of the cell that persisted for $>40 \mathrm{~min}$. Although these results suggest a persistent modification in the bioelectrical behavior of the VD neuron, the possibility that the changes induced by the sensitizing

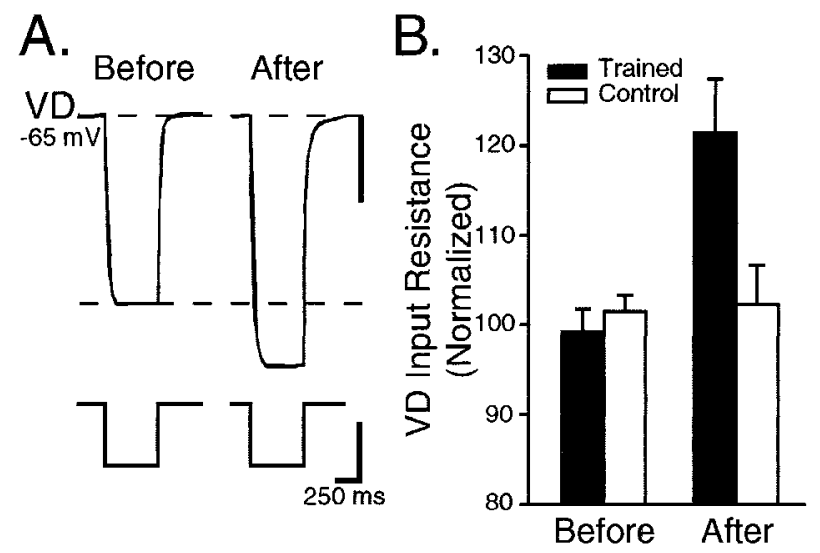

Figure 5. Change in input resistance of the VD neuron. $A$, In a VD neuron isolated in situ from the pyloric network, constant amplitude hyperpolarizing current $(-2 \mathrm{nA} ; 500 \mathrm{msec})$ pulses were applied before and $40 \mathrm{~min}$ after the sensitizing stimulation. After this stimulation, the hyperpolarization caused by the current pulse increased compared with before (bottom dashed line), indicating a training-induced increase in VD neuron input resistance. VD neuron membrane potential was held at -65 $\mathrm{mV}$ during testing (top dashed line). Calibration: $5 \mathrm{mV}, 2 \mathrm{nA}$. B, Comparison of VD neuron input resistance before and $40 \mathrm{~min}$ after the training period in trained (black bars) and control (white bars) groups $(n=$ 4 in each group). The input resistance increased significantly after training $\left(F=9.774, p<0.02\right.$; before vs after in trained group, $\mathrm{q}_{2}=6.471, p<$ 0.01 ; in control group, $\mathrm{q}_{2}=0.218$; between groups before training, $\mathrm{q}_{2}=$ 0.563; after training, $\mathrm{q}_{2}=4.814, p<0.01$ ).

stimulation result indirectly from an alteration in properties of other pyloric network neurons presynaptic to the VD neuron is not excluded.

To determine whether the sensitizing stimulation-induced modifications were at least in part attributable to a direct effect on the VD neuron itself, the neuron was isolated in situ from the pyloric network in two additional groups of trained $(n=4)$ and control $(n=4)$ preparations. In both groups, the resting potential of the isolated VD neuron was held at $-65 \mathrm{mV}$ to permit measurement of VD neuron input resistance without spontaneous activity. Input resistance was tested by injecting brief (500 $\mathrm{msec}$ ) hyperpolarizing ( $-2 \mathrm{nA})$ current pulses before and $40 \mathrm{~min}$ after training. Holding potential in the VD neuron was readjusted to $-65 \mathrm{mV}$ immediately before the testing procedure that was applied after training. No stimulation other than the sensitizing stimulation was used. As seen in Figure $5 A$, which illustrates the responses of a VD neuron from a trained preparation, membrane hyperpolarization in response to the same size current pulse was larger after the sensitizing stimulation than before. The statistical significance of this alteration in isolated VD neuron responsiveness is supported by comparisons between groups. Input resistance (calculated in each preparation as the mean value over a series of five successive pulses at $1 \mathrm{~Hz}$ ) significantly increased after the sensitizing stimulation compared with before and compared with the control group values (Fig. 5B).

This modification in input resistance of isolated VD neurons indicated that the membrane properties of the neurons are directly and persistently modified by the sensitizing stimulation. Thus, although a causal link between the change in VD neuron input resistance and the changes in firing and membrane potential has yet to be established, these data indicate that the VD neuron is itself one of several possible loci of sensitizationinduced plasticity in the pyloric network. 



Figure 6. Response of the VD neuron to stimulation of the IV neuron. $A$, In an intact control preparation, IV neuron stimulation by intracellular depolarizing current pulses (i) (pulse of $200 \mathrm{msec}$ at $55 \mathrm{~Hz}$ for $1 \mathrm{sec}$ ) produced both a burst of spikes and a transient inactivation of the spontaneous pyloric firing in the VD neuron. This response was similar to that induced by vpln stimulation (compare with Fig. $1 B$ ). B, A similar VD neuron response to IV neuron stimulation $(i)$ was obtained in a control preparation in which (1) polysynaptic pathways between the IV and VD neurons were suppressed by bathing the preparation (other than the STG) in a saline that blocked synaptic transmission and removing CoGs and (2) the VD neuron was isolated from the pyloric network. Oxotremorine $\left(10^{-5} \mathrm{M}\right)$ was then added to induce VD neuron oscillatory activity. Under these conditions the monosynaptic connection from the IV neuron was still able to elicit both a burst of spikes and transient inactivation of the VD neuron. Calibration: $10 \mathrm{mV}$.

\section{Contribution of the presynaptic IV neuron to VD neuron response}

The vpln does not monosynaptically contact any neurons of the pyloric network. Rather, it synaptically activates the cardiac sac network by eliciting bursting activity in the two IV neurons that in turn synapse onto several neurons, including the VD neuron (Hooper and Moulins, 1990). Thus, the IV neurons are suitably placed to contribute to the VD neuron inactivation induced by vpln stimulation and to changes in the inactivation duration resulting from training.

To test these possibilities, intrasomatic stimulation of IV neurons with depolarizing current pulses was used to determine their synaptic effects on the VD neuron. Stimulation with parameters ( $55 \mathrm{~Hz}$ for $1-1.5 \mathrm{sec}$ ) that mimicked IV neuron firing in response to vpln stimulation (see below) was used. Stimulation of an IV neuron elicited a barrage of EPSPs and a burst of spikes in the VD neuron and a transient VD neuron inactivation (Fig. 6A). This biphasic VD neuron response was qualitatively similar to that elicited by vpln stimulation (compare Figs. $6 A$ and $1 B$ ). Several lines of evidence suggest that the effects elicited by IV neuron stimulation on the VD neuron probably involved a monosynaptic connection. First, EPSPs in the VD neuron were elicited by IV action potentials with a one-for-one relationship at constant delay (data not shown) (Hooper and Moulins, 1990). Second, the

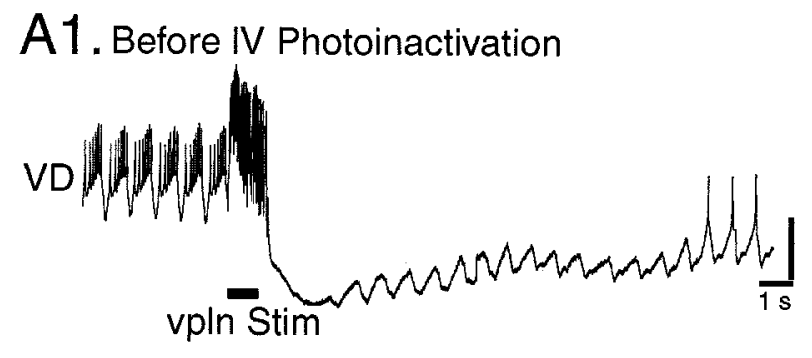

A2. After IV Photoinactivation
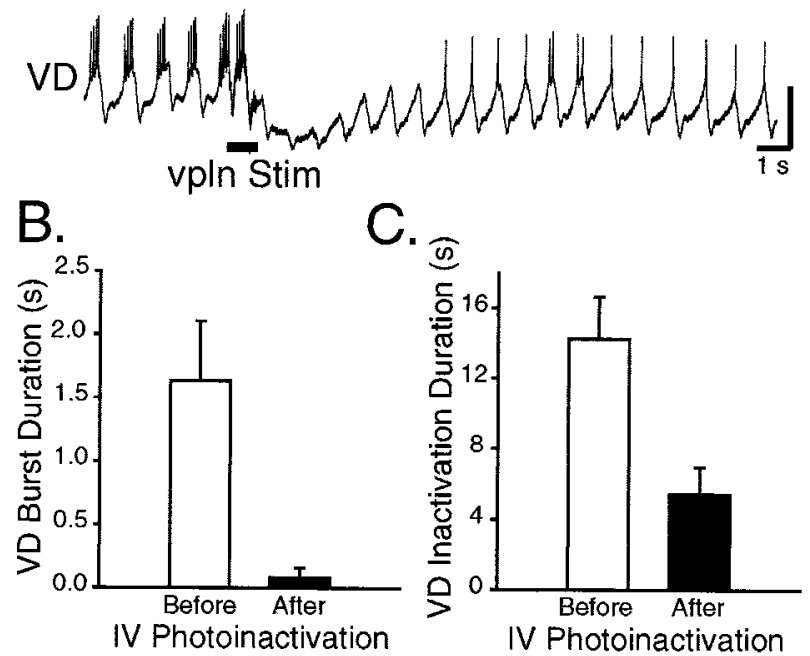

Figure 7. The IV neurons contribute to the vpln-elicited response in the VD neuron. Comparison of the responses elicited in a same VD neuron of a control preparation by vpln stimulation ( $40 \mathrm{~Hz}$ for $1 \mathrm{sec}, 5 \mathrm{~V}$ ) applied before $(A 1)$ and after $(A 2)$ IV neuron photoinactivation. The duration of the spike burst $(B)$ and the inactivation $(C)$ of the VD neuron significantly decreased after IV neuron photoinactivation (black bar) compared with before (white bar) $\left(t_{4}=3.157 ; p<0.05\right.$ in $B ; t_{4}=4.194 ; p<0.025$ in $C ; n=5)$. Calibration: $10 \mathrm{mV}$.

transient inactivation of spontaneous firing in the VD neuron persisted in preparations $(n=3)$ in which this neuron was isolated in situ from the pyloric network in the STG, and any polysynaptic pathways outside the STG were suppressed (when the CoGs were removed and the remainder of the preparation, with the exception of the STG, was bathed in a saline that blocked synaptic transmission) (Fig. 6B).

Direct evidence that the IV neurons contribute to convey vpln input to the VD neuron was provided by comparing the responses of a VD neuron to vpln stimulation before and after photoinactivation of the IV neurons. In all five preparations examined, the burst of spikes elicited in the VD neuron by vpln stimulation before photoinactivation (Fig. 7A1,B) was nearly abolished after photoinactivation (Fig. 7A2,B), and vpln stimulation-induced VD neuron inactivation was similarly decreased after photoinactivation compared with before (Fig. 7A,C).

Although other neuron input may be implicated, these results indicate that IV neuron input contributes importantly to both the cardiac sac drive to, and the transient inactivation of spontaneous pyloric firing by the VD neuron. Thus, long-lasting changes in the firing properties of cardiac sac IV neurons could contribute to the changes in VD neuron firing observed by rhythmic vpln stimulation after training. 

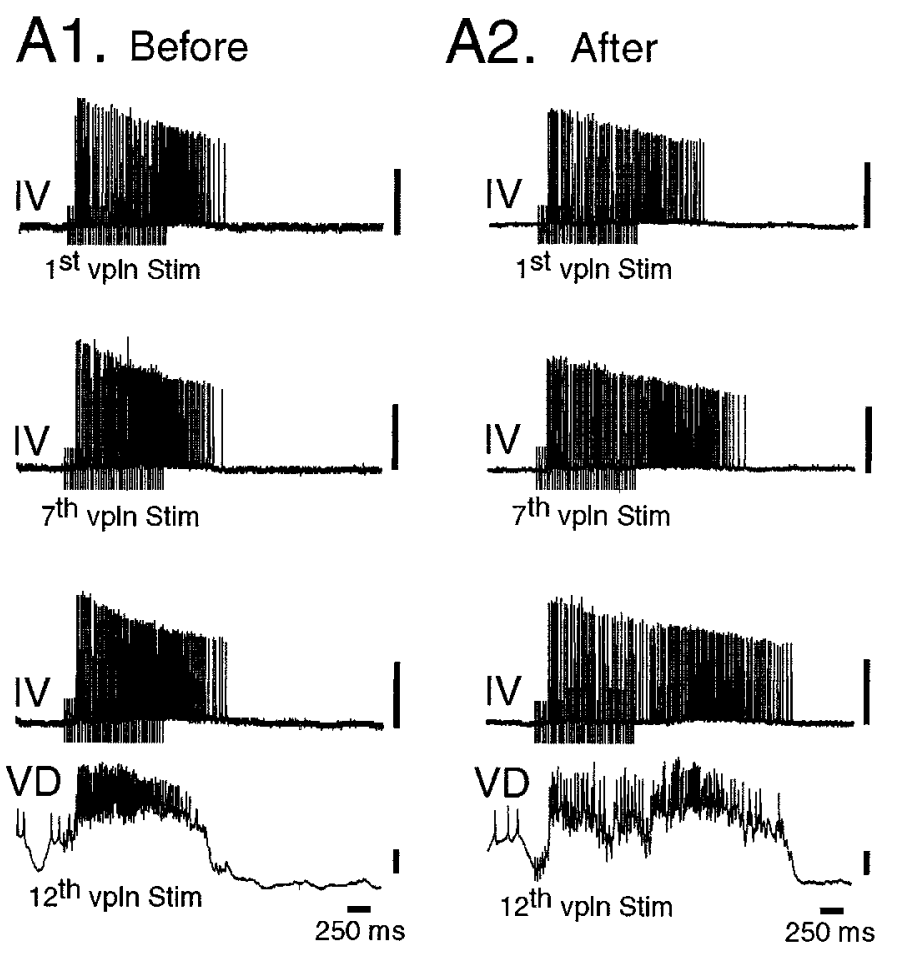

Figure 8. Change of bursting activity in IV neurons. Recording of IV neuron spike bursts elicited by the 1st (top traces), 7th (middle traces), and 12th (IV, bottom traces) vpln stimulation, before $(A 1)$ and 40 min after (A2) training. IV neuron bursts were constant before training but progressively increased during successive vpln stimulations after training. A similar change was recorded in VD neuron EPSPs and spike bursts (bottom traces). $\mathrm{A} 1$ and $\mathrm{A} 2$ were from the same preparation. Calibration: $5 \mathrm{mV}$.

\section{Induced plasticity in IV neuron bursting activity}

To investigate whether the sensitizing stimulation produces persistent changes in the firing properties of the IV neurons, IV neuron bursting activity elicited by rhythmic vpln stimulation was compared before and after training in the same preparations described earlier. A vpln initial stimulation (40 $\mathrm{Hz}$ for $1 \mathrm{sec}$ ) invariably elicited a powerful burst of spikes in the IV neuron (Fig. $1 B$ ). This burst, which was defined by $\geq 10$ spikes occurring with an instantaneous frequency of $\geq 6 \mathrm{~Hz}$, lasted $1.34 \pm 0.06 \mathrm{sec}$ with a mean frequency of $52.5 \pm 5.5 \mathrm{~Hz}$ (values are from both the control and trained groups before sensitizing stimulation; $n=20$ ).

In the control group, successive IV neuron bursts elicited by rhythmic vpln stimulation have a constant duration. A similar result was also found in the trained group before sensitizing stimulation (Figs. 8A1, 9A, left). However, 40 min after sensitizing stimulation, IV neuron burst duration progressively changed with repeated vpln stimulation (Figs. 8A2, 9A, right). Quantification of these vpln-elicited IV neuron bursts indicated that their duration increased only in the trained group and as a result of training (Fig. 9A). Moreover, this plasticity depended on the repetition of vpln stimulation in the post-training series. Thus, in the same preparations, the progressive increase in VD neuron inactivation is associated with an increase in the duration of presynaptic IV neuron firing.

This modification in the duration of IV neuron bursting was also associated with an increase in the duration of excitatory cardiac sac drive in the VD neuron (see VD traces in Fig. 8). This
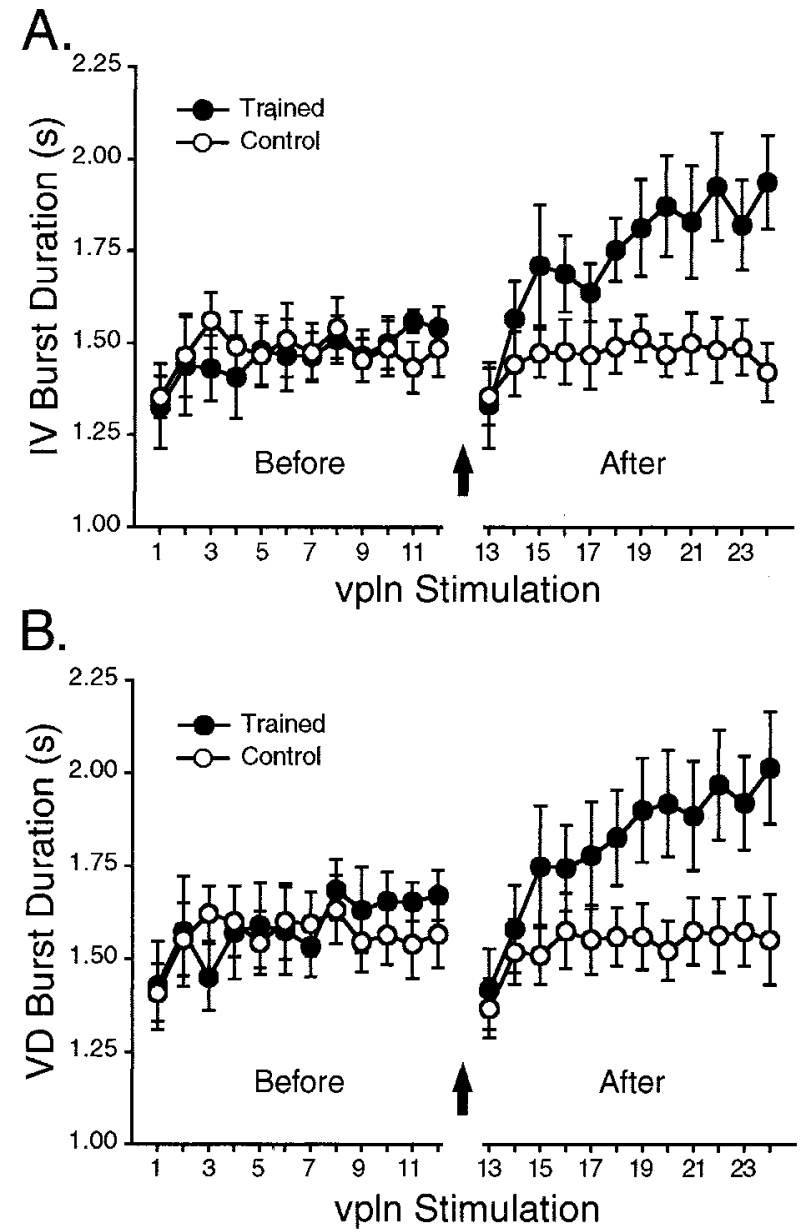

Figure 9. Increase in IV and VD neuron spike bursts. $A$, The duration of the IV neuron burst elicited by a series of vpln stimulation before and 40 min after training were compared in the trained (black dots; $n=$ 10 ) and the control groups (white dots; $n=10)$. Preparations were those described in Figure 3. After the sensitizing stimulation (arrow) the duration of the elicited IV neuron bursts progressively and significantly increased $(F=9.543, p<0.006$; before vs after in trained group, $\mathrm{q}_{2}=6.047, p<0.001$; in control group, $\mathrm{q}_{2}=0.132$; between groups before training, $\mathrm{q}_{2}=0.099$; after training, $\mathrm{q}_{2}=3.377, p<$ 0.025 ; effect of the repetition of vpln stimulation in the trained group after training, $F=6.623, p<0.001)$. $B$, In the same preparations as in $A$, the duration of the elicited bursts of EPSPs and action potentials in the VD neuron progressively and significantly increased in the trained preparations (black dots) after the sensitizing stimulation (arrow) compared with before and control values (white dots) $(F=8.826, p<$ 0.01 ; before vs after in trained group, $\mathrm{q}_{2}=5.318, p<0.002$; in control group, $\mathrm{q}_{2}=0.665$; between groups before training, $\mathrm{q}_{2}=0.229$; after training, $\mathrm{q}_{2}=2.945, p<0.05$; effect of the repetition of vpln stimulations in the trained group after training: $F=6.209, p<0.001$ ).

drive, which was defined by a barrage of EPSPs $>1 \mathrm{mV}$ at $\geq 6 \mathrm{~Hz}$ and action potentials differed according to training. Its duration increased only in the trained group after the sensitizing stimulation (Fig. 9B). This change resulted in a progressive and significant increase in VD neuron burst duration in response to successive post-training vpln stimulations.

These results thus indicate that the sensitizing stimulation persistently modifies the response of IV to vpln stimulation and that the change in the cardiac sac network is correlated with changes both in the cardiac sac drive and inactivation of the postsynaptic VD neuron. 


\section{Plasticity in IV and VD neurons are both essential}

In a next step, the relative importance of these changes in the presynaptic (IV) and postsynaptic (VD) neurons for expression of VD neuron pattern switching after training was assessed. This was done by direct experimental manipulation of the functional state of the IV and/or VD neurons to mimic neuronal responses during post-training periods and examining the resulting effect on the capacity of the VD neuron to express pattern switching.

First, bursting activity in the IV neurons, which activates the cardiac sac network and drives the cardiac sac burst in the VD neuron was generated by stimulating either an IV soma with intracellular depolarizing current pulses or the IV neuron axons with extracellular stimulation of the ivn. The frequency and duration of this stimulation was adjusted to mimic the successive bursts of activity in the IV neuron elicited by a series of vpln stimulations before and after a successful training (see Materials and Methods). Second, spontaneous pyloric firing in the VD neuron was manipulated by changing its membrane potential with continuous intracellular current injection. The experiments were conducted in four groups of preparations ( $n=5$ in each group) that were selected after sensitizing stimulation for their ability to express the progressive increase in VD neuron inactivation duration during a series of vpln stimulations $(F=6.142 ; p<0.001)$. Subsequently, these successfully sensitized preparations (20 of 29 preparations) were randomly assigned to one of the following groups.

In a first group (group 1), training-induced plasticity in the IV neurons was mimicked by successive IV neuron stimulation with progressively increasing duration. In this group, the VD neuron membrane potential was not modified from its post-training value $(-70.4 \pm 1.1 \mathrm{mV})$. In this case, both IV and VD neuron plasticity were expressed (Fig. 10A1). In a second group (group 2), only IV neuron plasticity was expressed. The same protocol of IV neuron stimulation as for group 1 was used, but the post-training hyperpolarization of the VD neuron was compensated for by a tonic depolarization of the cell (Fig. 10A2). The membrane potential between spontaneous VD neuron oscillations was set to $-60 \mathrm{mV}$ to allow the VD neuron to generate spiking activity equivalent to that recorded in pre-trained VD neuron (see below). In the remaining two groups, the IV neurons were repetitively stimulated (with a $30 \mathrm{sec}$ period) with a constant duration to mimic IV neuron bursts in control preparations. In one of those groups (group 3), VD neuron membrane potential was not changed from its post-training value $(-68.9 \pm 0.8 \mathrm{mV})$. Thus, only plasticity in the VD neuron was allowed to be expressed (Fig. 10B1). In the second of those groups (group 4), the post-training hyperpolarization of the VD neuron was again compensated for by a tonic depolarization of the cell to $-60 \mathrm{mV}$ (Fig. 10B2). Thus, in this final group neither IV nor VD neuron plasticity were allowed to be expressed.

The effectiveness of the various paradigms of IV neuron stimulation and VD neuron repolarization in these groups was assessed by comparing the duration of the cardiac sac burst elicited in the VD neuron and the number of spikes per burst of pyloric activity. A progressive and significant increase in duration of cardiac sac drive to the VD neuron was observed during successive IV neuron stimulations of increasing duration (group $1, F=$ 79.659, $p<0.001$; group $2, F=189.819, p<0.001)$. By contrast, no significant change in VD neuron burst duration was observed when it was elicited by successive IV neuron stimulation of constant duration (group 3, $1.27 \pm 0.01 \mathrm{sec}, F=1$; group 4, $1.25 \pm$
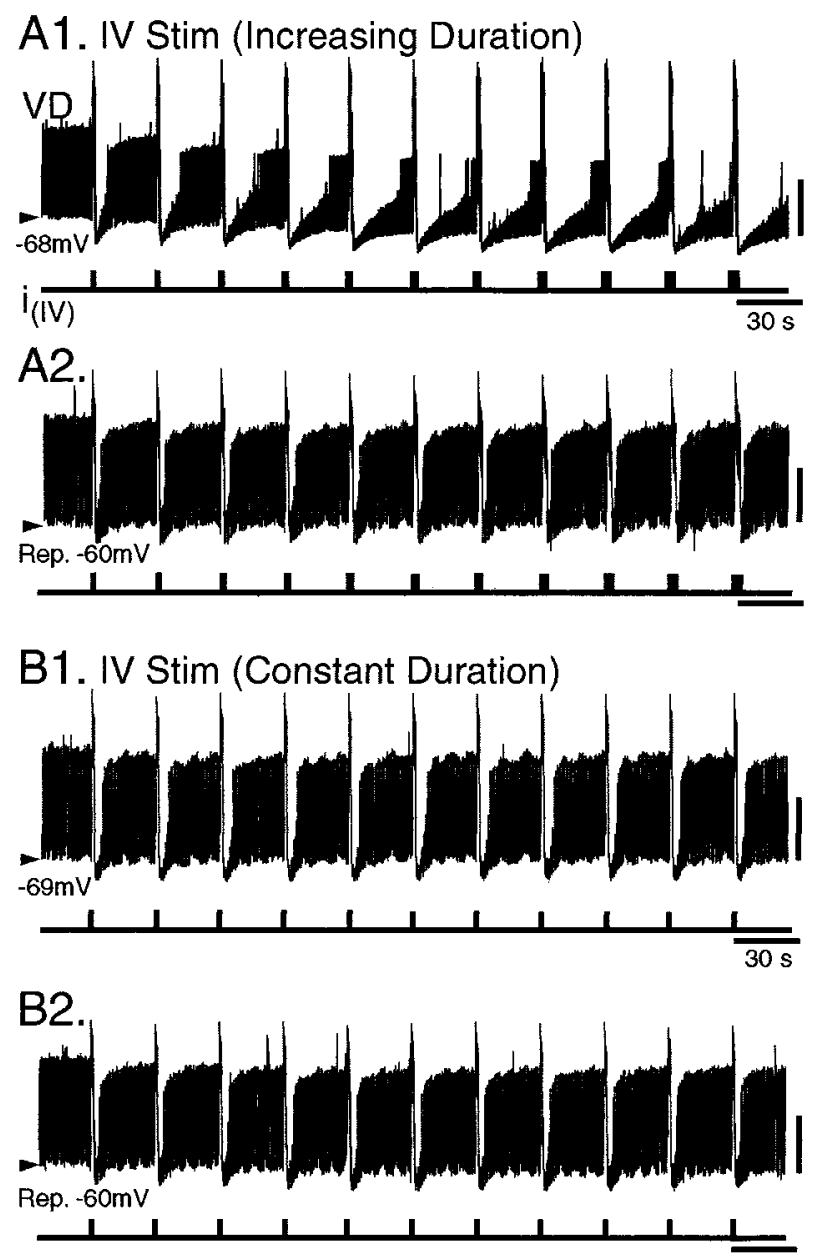

Figure 10. Relative contribution of IV and VD neuron changes in trained preparations. In four preparations that were trained previously, IV was rhythmically (with a $30 \mathrm{sec}$ period) stimulated with either a progressively increasing duration $\left(A ; 1.2-2.3 \mathrm{sec}\right.$ in steps of $0.1 \mathrm{sec} ; i_{(I V)}$ a schematic representation of the stimulation) or with a constant duration $(B ; 1.2 \mathrm{sec})$. The membrane potential in the VD neuron (arrowheads) was either not manipulated $(A 1,-68 \mathrm{mV} ; B 1,-69 \mathrm{mV})$ or was repolarized to $-60 \mathrm{mV}$ by tonic injection of depolarizing current $(A 2, B 2)$. In these trained preparations, changes in VD neuron inactivation duration were expressed only when both the IV neuron was rhythmically stimulated with a progressively increasing duration to mimic IV neuron firing after training and the VD neuron membrane potential was allowed to remain at its post-training value (i.e., A1). Calibration: $10 \mathrm{mV}$.

$0.02 \mathrm{sec}, F=0.845)$. Moreover, the repolarization of the VD neuron significantly increased the number of action potentials per burst in the manipulated VD neuron (group 2, $8.6 \pm 1.1$ spikes/ burst; group 4, $7.5 \pm 1.3$ spikes/burst) compared with the nonmanipulated neuron (group 1, $4.5 \pm 0.4$ spikes/burst; group 3, $4.7 \pm 0.5$ spikes/burst; $F=4.671, p<0.02$ ). Thus, the experimental paradigms of IV neuron stimulation and VD neuron repolarization were able to induce or suppress at least some features of the training-induced plasticity.

As was expected for trained preparations, the first group expressed a progressive increase in VD neuron inactivation duration during successive IV neuron stimulations of increasing duration (Figs. 10A1). This increase in group 1 was significant compared with the three other groups (Fig. 11). No significant change in inactivation was observed among the three other groups. 


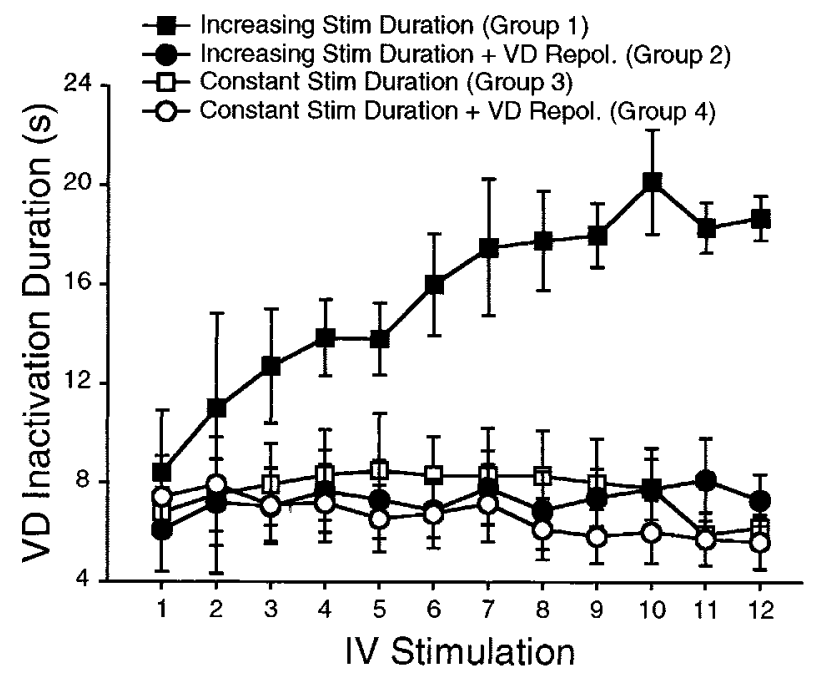

Figure 11. Comparison of the relative contribution of IV and VD neuron changes. The VD inactivation duration elicited by successive IV stimulations was compared in four groups of previously trained preparations ( $n=5$ in each group). These groups were submitted to the experimental paradigms described in Figure 10. The VD neuron inactivation duration progressively and significantly increased only in the group in which both the IV neurons were stimulated with a progressively increasing duration and the VD neuron membrane potential was at its posttraining value (black squares). Such an increase of VD neuron inactivation duration was not induced by IV neuron stimulation with increasing duration while the VD neuron was repolarized to $-60 \mathrm{mV}$ (black circles) or by IV neuron stimulation with a constant duration while the VD neuron membrane potential was either at its post-training value (white squares) or was repolarized to $-60 \mathrm{mV}$ (white circles) $(F=5.110, p<$ 0.001; group 1 vs groups $2,3,4, \mathrm{q}_{3}=5.506, p<0.005 ; \mathrm{q}_{2}=4.999, p<$ $0.005 ; \mathrm{q}_{4}=5.918, p<0.005$; group 2 vs groups $3,4, \mathrm{q}_{2}=0.390 ; \mathrm{q}_{2}=0.412$; group 3 vs $\left.4, q_{3}=0.793\right)$.

These results therefore suggested that both a progressive increase in IV neuron burst duration and a hyperpolarization of the VD neuron are required for the expression of the progressive increase in the duration of VD neuron inactivation (i.e., conditions met in group 1). Blocking the increases of either IV neuron burst duration (group 2) or VD neuron membrane potential alone (group 3 ) as well as blocking changes in both (group 4) was sufficient to prevent the VD neuron from losing its spontaneous pyloric behavior and switching to cardiac sac activity. Thus, training-induced plasticity not only occurred in different functional networks, but the co-occurrence of these changes in both networks seems necessary for the VD neuron to switch from one network to another.

\section{Cooperativity of changes in IV and VD neuron activity}

IV and VD neuron activity influences the activity of other neurons in the cardiac sac and pyloric networks. Thus, in previously trained preparations, manipulations of IV and/or VD neuron activity could exert their effects indirectly through other training-induced changes in these networks. Conversely, if the IV and VD neurons themselves are determinants in VD neuron pattern switching, one would expect to be able to induce switching by manipulating IV and VD neuron activity in nonsensitized control preparations.

To test this possibility, four additional groups of preparations ( $n=10$ per group) were used. All preparations were selected before experiments for their ability to express a constant VD inactivation duration in response to an initial series of rhythmic vpln stimulations $(40 \mathrm{~Hz}$ for $1 \mathrm{sec}$ at an interval of $30 \mathrm{sec} ; F=$
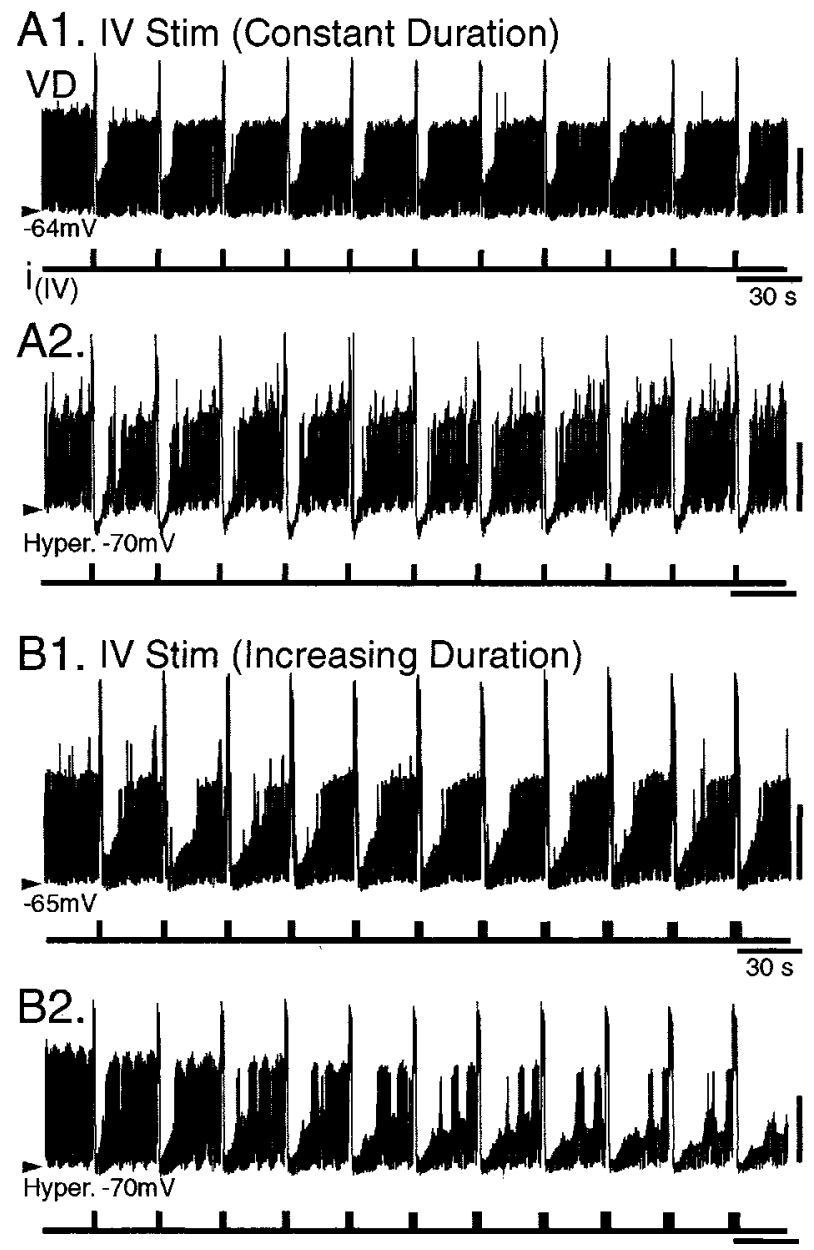

Figure 12. VD neuron switching mimicked by manipulating IV neuron activity and VD neuron membrane potential in control preparations. In four control preparations, the IV neurons were repetitively (with a $30 \mathrm{sec}$ period) stimulated either with a constant duration $\left(B ; 1.2 \mathrm{sec} ; i_{(I V)}\right.$ a schematic representation of the stimulation) or with a progressively increasing duration $(A ; 1.2-2.3 \mathrm{sec}$ with step of $0.1 \mathrm{sec})$. The VD neuron membrane potential (arrowheads) was either not altered $(A 1,-64 \mathrm{mV}$; $B 1,-65 \mathrm{mV}$ ) or was hyperpolarized to $-70 \mathrm{mV}$ by a tonic injection of hyperpolarizing current $(A 2, B 2)$. A progressive increase in VD neuron inactivation duration was elicited only when both the IV neuron was stimulated with a progressively increasing duration and the VD neuron was hyperpolarized (B2). Thus, in control preparations, VD neuron switching could be mimicked only if both IV neuron firing and VD neuron membrane potential were altered. Calibration: $10 \mathrm{mV}$.

1.142). These control preparations were randomly assigned to one of the following groups.

In group 1, the IV neurons were stimulated to mimic the successive vpln-elicited IV neuron firing observed in control preparations (i.e., the neurons IV were repetitively stimulated at constant duration for a $30 \mathrm{sec}$ period), and VD neuron membrane potential was not changed from its control value $(-64.7 \pm 0.7$ $\mathrm{mV})$. Thus, neither plasticity in the IV neurons nor VD neuron were mimicked in these preparations (Fig. 12A1). In group 2, only the change in VD neuron membrane potential was mimicked (Fig. 12A2). Thus, the same IV neuron stimulus paradigm as in group 1 was used, but a tonic hyperpolarization of the VD neuron was imposed to bring its membrane potential between pyloric oscillations to a value $(-70 \mathrm{mV})$, close to that recorded after training (Fig. 4). In group 3, only the change in IV neuron burst 


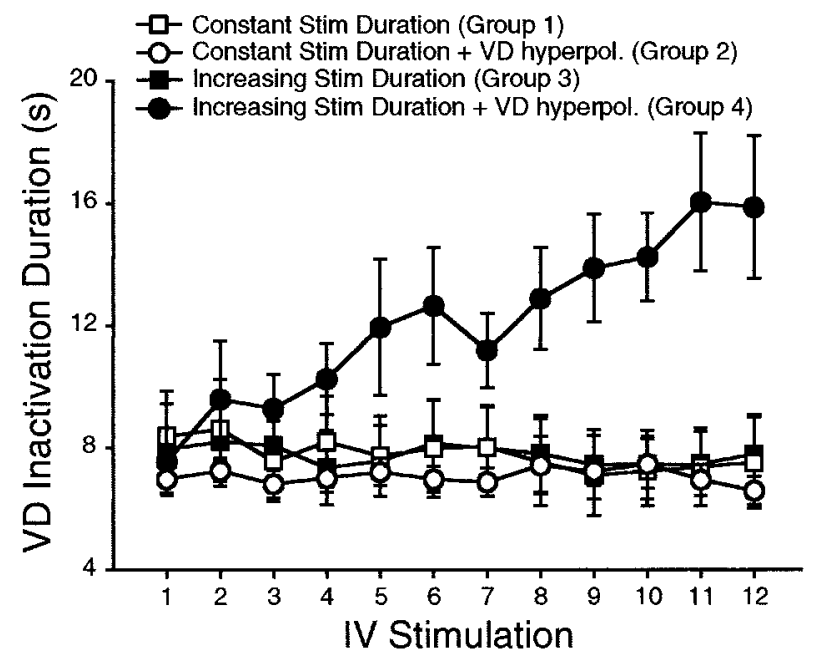

Figure 13. Increase in VD neuron inactivation duration in control preparations. The VD neuron inactivation duration elicited by successive IV neuron stimulations was compared in four groups of control preparations ( $n=10$ in each group). These groups were submitted to the experimental paradigms described in Figure 12. VD neuron inactivation duration progressively and significantly increased only when both the IV neurons were stimulated with a progressively increasing duration and VD neuron membrane potential was hyperpolarized to $-70 \mathrm{mV}$ (black circles). If only IV neuron stimulation duration (black squares) or VD neuron membrane potential (white circles) or neither (white squares) were changed, VD neuron inactivation duration remained constant. Cooperative changes in both presynaptic IV neuron firing and in the membrane potential of the postsynaptic VD neuron were required to express VD neuron motor pattern switching $\left(F=7.039, p<0.001\right.$; group 4 vs groups $1,2,3, \mathrm{q}_{2}=$ $3.601, p<0.02 ; \mathrm{q}_{4}=4.003, p<0.04$ and $\mathrm{q}_{3}=3.601, p<0.04$; group 1 vs groups $2,3, \mathrm{q}_{2}=0.392, \mathrm{q}_{3}=0.402$; group 2 vs group $3, \mathrm{q}_{2}=0.001$ ).

duration was mimicked. Successive (at $30 \mathrm{sec}$ intervals) IV neuron stimulation with progressively increasing duration was used, but VD neuron membrane potential was not modified from its control value $(-65.2 \pm 0.5 \mathrm{sec})$ (Fig. 12B1). Finally, in group 4 the changes in both the IV and VD neurons were experimentally mimicked; an increasing stimulation duration was imposed on the IV neuron while the VD neuron was tonically hyperpolarized to $-70 \mathrm{mV}$ (Fig. 12B2).

The effectiveness of the different IV neuron stimulation and VD neuron hyperpolarization paradigms was tested by analyzing the duration of the cardiac sac burst and the number of spikes per spontaneous pyloric burst in the VD neuron. Successive IV neuron stimulation of constant duration elicited successive constant duration cardiac sac bursts in the VD neuron (group 1, $1.22 \pm 0.12 \mathrm{sec}, F=0.934$; group $2,1.21 \pm 0.12 \mathrm{sec}, F=0.872$ ). Stimulation of the IV neuron of increasing duration elicited progressively longer cardiac sac bursts (group 3, $F=167.497, p<$ 0.001 ; group $4, F=218.632, p<0.001$ ). VD neuron hyperpolarization significantly decreased the number of spikes generated on pyloric-timed oscillations (group 2, $4.5 \pm 0.8$ spikes/burst; group 4, $4.1 \pm 0.8$ spikes/burst) compared with firing in nonmanipulated VD neurons (group 1, $6.9 \pm 0.7$ spikes/burst; group 3, $6.7 \pm 0.8$ spikes/burst; $F=3.539, p<0.025)$. Thus, graded IV neuron stimulation and VD neuron hyperpolarization reliably modified the firing of these neurons and mimicked some of the major aspects of the training-induced plasticity.

A significant difference in VD neuron mean inactivation duration that depended on repeated IV neuron stimulation was also found among groups (Figs. 12, 13). VD neuron inactivation duration increased in group 4 compared with the three other groups in which no significant change in VD neuron inactivation duration was found. Thus, simply stimulating the IV neurons successively with constant duration (group 1) (Figs. 12A1, 13) is not sufficient to progressively modify VD neuron inactivation duration. Similarly, changes in either VD neuron membrane potential or IV neuron firing duration alone (groups 2 and 3, respectively) (Figs. 12A2, 13) are not able to progressively suppress VD neuron pyloric firing and switch it to the cardiac sac pattern. In contrast, changing the firing properties of both presynaptic and postsynaptic cells (group 4) (Figs. 12B2, 13) progressively increased the duration of the cardiac sac drive to the VD neuron and the duration of the inactivation of VD neuron pyloric firing.

Thus, in control preparations, the VD neuron can be switched from the pyloric to the cardiac sac pattern as a result of cooperative changes evoked presynaptically in the IV neurons and postsynaptically in the VD neuron.

\section{DISCUSSION}

A considerable body of evidence is accumulating on neuronal mechanisms by which training long-lastingly strengthens expression of a specific motor response (for review, see Kandel and Schwartz, 1982; Carew and Sahley, 1986; Byrne, 1987; Glanzman, 1995; Lechner and Byrne, 1998). Much less is known about neuronal mechanisms by which training switches a behavior from one motor program to another. Such motor program switching induced by training is a widespread phenomenon that improves various behaviors, including rhythmic behaviors (Shashoua, 1976; Brainard and Doupe, 2000; Nadler et al., 2000; Plautz et al., 2000; Doupe and Kuhl, 1999; Sanes, 2000). Thus, understanding mechanisms by which CNSs switch motor programs as a result from past sensory stimulation may help to understand neuronal basis of such motor learning.

In the isolated lobster stomatogastric nervous system, a sensitizing mechanosensory stimulation induces a long-lasting capability for the VD neuron to switch its activity from one activity pattern to another. The VD motor neuron, which governs dilation of the intervening valve between the cardiac sac and the pyloric chamber of the foregut, expresses spontaneously the pyloric pattern. After a sensitizing stimulation, the VD neuron acquired, for several hours, capability to express the cardiac sac pattern (Nargeot and Moulins, 1997). The present study indicates that this training-induced pattern switching in a motor neuron is mediated by persistent changes in a neuronal cooperation between two interacting pattern-generating networks.

\section{Plasticity in interactions between neuronal networks}

It is already known that distinct neuronal networks interact to coordinate their functioning on a short- or long-lasting basis (Gray and Singer, 1989; Sporns et al., 1989; Clemens et al., 1998; Bartos et al., 1999; Parker and Grillner, 2000). In some cases, such interactions can permit individual neurons to lose their allegiance with one network and become functional members of another network (Hooper and Moulins, 1989; Meyrand et al., 1991; Weimann and Marder, 1994; Hess and Donoghue, 1994; Darian and Gilbert, 1995; Rioult-Pedotti et al., 1998) (see also Buonomano and Merzenich, 1998). The role of synaptic connections between networks in short-lasting network reconfiguration has been illustrated (Sporns et al., 1989; Dickinson et al., 1990). However, it is unclear how these internetwork connections may underlie persistent network reconfigurations to mediate longlasting motor pattern switching after training. 


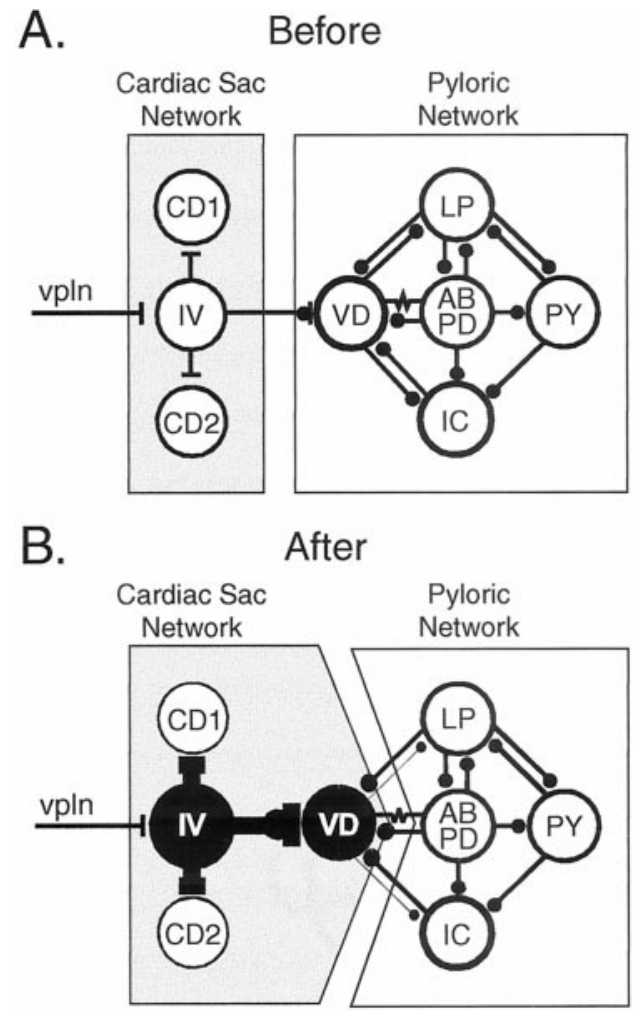

Figure 14. Cooperation of plasticity in VD neuron switching. The stomatogastric nervous system contains at least two neuronal networks devoted to distinct biological functions (i.e., cardiac sac network, gray box; and the pyloric network, white box; large circles symbolize cell bodies; chemical inhibitory, excitatory, and electrical synapses are indicated by small filled circles, dashes, and resistance symbol, respectively). When the cardiac sac network is silent, the VD neuron expresses a rhythmic activity specific to the pyloric network. The sensory nerve vpln elicits a powerful burst of spikes in the IV neuron, and probably other neurons, which triggers activity in the cardiac sac network. This IV neuron activity (and possibly others) monosynaptically excites the VD neuron and transiently inactivates spontaneous VD neuron pyloric firing. $A$, Before training, the $\mathrm{VD}$ neuron response is not strong enough to allow the VD neuron to lose its pyloric firing during successive vpln stimulations. $B$, After training (stimulation of the contralateral vpln), persistent changes occur in both networks. First, IV neuron firing is progressively strengthened in response to successive vpln stimulation. Second, VD neuron pyloric activity weakens as the neuron hyperpolarizes and its input resistance increases. These presynaptic and postsynaptic changes cooperate to suppress VD neuron pyloric firing and switch its activity to the cardiac sac pattern.

In the present study, changes associated with the long-lasting VD motor neuron switching capability are expressed in both the pyloric and the cardiac sac networks (Fig. 14). First, in the cardiac sac network, the firing properties of the IV pattern-generating neurons are progressively increased. This functional plasticity is expressed during rhythmic stimulation of a vpl mechanosensory nerve and results in an increased IV neuron-mediated cardiac sac drive to the VD neuron. Second, in the pyloric network, spontaneous firing in the VD neuron that renders this cell spontaneously active with this network is persistently weakened as VD neuron membrane potential hyperpolarizes and the input resistance of the neuron increases. At least some of these changes are intrinsic to the VD neuron, although a contribution of network changes in addition to those described here cannot yet be excluded. The cardiac sac and pyloric networks interact; a monosynaptic IV to VD neuron connection provides a functional link between these networks (Fig. 14) (see also Sigvardt and Mulloney, 1982; Hooper and Moulins, 1990).

Thus, the present study provides direct evidence that both presynaptic and postsynaptic elements that are engaged in an internetwork connection contribute to motor neuron pattern switching induced by a training procedure. An important result is that plasticity underlying such pattern switching is not confined either to a single neuron or within a specific neuronal network. Rather, plasticity is distributed between different networks in which some neurons cooperate to change motor neuron activity.

\section{Neuronal cooperation in long-lasting network reconfigurations}

The cooperation of different neuronal processes can govern induction of neuronal plasticity. Coactivation of both presynaptic and postsynaptic neurons in a circuit (Hawkins et al., 1983; Walters and Byrne, 1983; Frégnac et al., 1988; Lin and Glanzman, 1994; Bao et al., 1997) (see Brown et al., 1990; Frégnac, 1996), or of different molecular pathways in a same cell (Sherff and Carew, 1999), can be required for induction of long-lasting cellular changes. In the present study, the cellular mechanisms underlying the actual induction of the plasticity during training were not investigated. Rather, the data concern mechanisms governing expression of the plasticity subsequent to its induction. A fascinating finding is the demonstration that expression of plasticity in both presynaptic (IV) and postsynaptic (VD) neurons is required to strengthen the relationship between these neurons and allow VD motor neuron switching. This switching capability was completely abolished by preventing expression of changes in either the presynaptic or the postsynaptic neuron. Similarly, it was impossible to express the neuronal switching by mimicking changes in either the presynaptic or the postsynaptic neuron alone, whereas mimicking both changes permitted it. Thus, the network reconfiguration did not result from a simple cooccurrence of unrelated changes in different elements of a neuronal connection. Rather, the strength of the neuronal relationship and the resulting neuronal switching emerged from a cooperative action of both the presynaptic and postsynaptic plasticity.

Evidences from a number of studies have indicated that persistent cellular changes induced by past sensory experiences or experimental paradigms of patterned neuronal stimulation can be expressed conjointly at different loci in a network (Frost et al., 1988; Lockery and Sejnowski, 1993; Cleary et al., 1998; Bi and Poo, 1999; Spencer et al., 1999; Staras et al., 1999). However, necessity of a cooperation among such different sites of plasticity has not been investigated. The present results provide evidences that a cooperation between plasticity that are expressed in two neurons initially belonging to different networks may be essential for network reconfigurations and motor pattern switching expressed after a training procedure.

\section{Mechanisms for cooperative neuronal plasticity}

The sensitizing-induced plasticity modified firing properties of both the presynaptic IV and postsynaptic VD neurons. The IV neuron bursting activity mediates both large EPSPs responsible for the strong cardiac sac drive to the VD neuron and a modulator effect that inactivates for several seconds the VD neuron pyloric firing. This inactivation is not a consequence of the strong VD neuron firing produced by the IV neuron-elicited EPSPs (Hooper and Moulins, 1990). Rather, the IV neurons release cotransmitters that elicit EPSPs and modulate the regenerative 
membrane properties required for VD neuron to spontaneously generate the pyloric activity (Fig. 6B) (Hooper and Moulins, 1989). Modulator neurons are known to play a critical role in controlling short-term neuronal network functioning (Nagy and Dickinson, 1983; Mackey et al., 1989) (see Harris-Warrick and Marder, 1991; Xu et al., 1994), but, their roles in expression of persistent network changes remain unclear. The present study suggests that modulator neurons may contribute to long-lasting network changes not only through modifications in properties of their postsynaptic target neurons, but also by changes in their own firing properties. Such changes in modulator neuron activity may contribute to reorganize network functioning and switch a motor activity from one pattern to another.

The modulator effect of the presynaptic IV neuron is partly gated by membrane properties of the postsynaptic VD neuron. By changing VD neuron membrane properties either by training or by experimental membrane hyperpolarization, the IV neuroninduced inactivation duration in the VD neuron either remains constant or gradually increases. Postsynaptic receptor sensitivity may contribute to such an effect. This sensitivity can alter with postsynaptic membrane potential and as such a modification in this potential could modify responses to a presynaptic input (Magazanik and Vyskocil, 1970; Fiekers et al., 1980; Magleby and Pallota, 1981; Takeyasu et al., 1983). However, the range of potentials required for such postsynaptic regulation may not be compatible with the observed plasticity in the VD neuron membrane potential (Changeux and Heidmann, 1987). Rather, the data suggest that the changes involve the electrical membrane properties of the VD neuron. Intrinsic membrane properties govern neuron excitability and in turn modify neuronal responses elicited by presynaptic input (Pinsker and Kandel, 1977; Llinas and Lopez-Barneo, 1988; Turrigiano et al., 1994, 1998; Golowasch et al., 1999; Turrigiano and Nelson, 2000). Thus, persistent changes in membrane conductances underlying such dynamic electrical properties may alter the response of postsynaptic neurons to their presynaptic modulatory input. Intrinsic regenerative properties allow the VD neuron to participate in the pyloric pattern (Hooper and Moulins, 1989). When sufficiently strong, these endogenous properties permit the VD neuron to only weakly respond to changes in presynaptic IV neuron firing. Conversely, persistent weakening of these dynamical membrane properties may render the VD neuron more responsive to changing IV neuron input. Thereby, changes in postsynaptic membrane properties may be fundamental to allow a cooperation of presynaptic and postsynaptic plasticity. Future studies would investigate these possibilities as well as the mechanisms by which such cooperative plasticity is induced in both presynaptic and postsynaptic neurons by training.

\section{REFERENCES}

Bal T, Nagy F, Moulins M (1988) The pyloric central pattern generator in crustacea: a set of conditional neuronal oscillators. J Comp Physiol 163:715-727.

Bal T, Nagy F, Moulins M (1994) Muscarinic modulation of a patterngenerating network: control of the neuronal properties. J Neurosci 14:3019-3035.

Bao JX, Kandel ER, Hawkins RD (1997) Involvement of pre- and postsynaptic mechanisms in posttetanic potentiation at Aplysia synapse. Science 275:969-973.

Bartos M, Manor Y, Nadim F, Marder E, Nusbaum MP (1999) Coordination of fast and slow rhythmic neuronal circuits. J Neurosci 19:6650-6660

Baxter DA, Patel VC, Byrne JH (1997) Computational model of a multifunctional central pattern generator $(\mathrm{CPG})$ that underlies consummatory feeding behavior of Aplysia. Soc Neurosci Abstr 23:1044.

Benjamin PR, Staras K, Kemenes G (2000) A systems approach to the cellular analysis of associative learning in the pond snail Lymnaea. Learn Mem 7:124-131.

Bi G, Poo M (1999) Distributed synaptic modification in neural networks induced by patterned stimulation. Nature 401:792-796.

Bianchi AL, Denavit-Saubié M, Champagnat J (1995) Central control of breathing in mammals: neuronal circuitry, membrane properties, and neurotransmitters. Physiol Rev 75:1-45.

Bidaut M (1980) Pharmacological dissection of the pyloric network of the lobster stomatogastric ganglion using picrotoxin. J Neurophysiol 44:1089-1101.

Brainard MS, Doupe AJ (2000) Interruption of a basal ganglia-forebrain circuit prevents plasticity of learned vocalizations. Nature 404:762-766.

Brown TH, Kairiss EW, Keenan CL (1990) Hebbian synapses: biophysical mechanisms and algorithms. Annu Rev Neurosci 13:475-511.

Buonomano DV, Merzenich MM (1998) Cortical plasticity: from synapses to maps. Annu Rev Neurosci 21:149-186.

Byrne JH (1987) Cellular analysis of associative learning. Physiol Rev 67:329-439.

Carew TJ, Sahley CL (1986) Invertebrate learning and memory: from behavior to molecules. Annu Rev Neurosci 9:435-487.

Changeux J-P, Heidmann T (1987) Allosteric receptors and molecular models of learning. In: Synaptic function (Edelman GM, Gall WE, and Cowan WM, eds), pp 549-601. New York: Wiley.

Claiborne BJ, Selverston AI (1984) Localization of stomatogastric IV neuron cell bodies in lobster brain. J Comp Physiol [A] 154:27-32.

Clark SA, Allard T, Jenkins WM, Merzenich MM (1988) Receptive field in the body map in adult cortex defined by temporally correlated inputs. Nature 332:444-445.

Clemens S, Combes D, Meyrand P, Simmers J (1998) Long-term expression of two interacting motor pattern-generating networks in the stomatogastric system of freely behaving lobster. J Neurophysiol 79:1396-1408.

Cleary LJ, Lee WL, Byrne JH (1998) Cellular correlates of long-term sensitization in Aplysia. J Neurosci 18:5988-5998.

Darian SC, Gilbert CD (1995) Topographic reorganization in the striate cortex of the adult cat and monkey is cortically mediated. J Neurosci 15:1631-1647.

Dickinson PS (1995) Interactions among neural networks for behavior. Curr Opin Neurobiol 5:792-798.

Dickinson PS, Mecsas C, Marder E (1990) Neuropeptide fusion of two motor-pattern generator circuits. Nature 344:155-158.

Doupe AJ, Kuhl PK (1999) Birdsong and human speech: common themes and mechanisms. Annu Rev Neurosci 22:567-631.

Edeline J-M (1998) Learning-induced physiological plasticity in the thalamo-cortical sensory systems: a critical evaluation of receptive field plasticity, map changes and their potential mechanisms. Prog Neurobiol 57:165-224.

Eisen JS, Marder E (1984) A mechanism for production of phase shifts in a pattern generator. J Neurophysiol 51:1375-1393.

Fiekers JF, Spannbauer PM, Scubon-Mulieri B, Parsons RL (1980) Voltage-dependence of desensitization. Influence of calcium and activation kinetics. J Gen Physiol 75:511-529.

Frégnac Y (1996) Dynamics of functional connectivity in visual cortical networks: an overview. J Physiol (Paris) 90:113-139.

Frégnac Y, Shulz D, Thorpe S, Bienenstock E (1988) A cellular analogue of visual cortical plasticity. Nature 333:367-370.

Frost WN, Clark GA, Kandel ER (1988) Parallel processing of shortterm memory for sensitization in Aplysia. J Neurobiol 19:297-334.

Glanzman DL (1995) The cellular basis of classical conditioning in Aplysia californica-it's less simple than you think. Trends Neurosci 18:30-36.

Golowasch J, Casey M, Abbott LF, Marder E (1999) Network stability from activity-dependent regulation of neuronal conductances. Neural Comput 11:1079-1096.

Gray CM, Singer W (1989) Stimulus-specific neuronal oscillations in orientation columns of cat visual cortex. Proc Natl Acad Sci USA 86:1698-1702.

Harris-Warrick RM, Marder E (1991) Modulation of neuronal network for behavior. Annu Rev Neurosci 14:39-57.

Harris-Warrick RM, Marder E, Selverston AI, Moulins M (1992) Dynamic biological networks: the stomatogastric nervous system (HarrisWarrick RM, Marder E, Selverston AI, and Moulins M, eds). Cambridge, MA: MIT.

Hawkins RD, Abrams TW, Carew TJ, Kandel ER (1983) A cellular mechanism of classical conditioning in Aplysia: activity-dependent amplification of presynaptic facilitation. Science 219:400-404.

Hess G, Donoghue JP (1994) Long-term potentiation of horizontal connections provides a mechanism to reorganize cortical motor maps. J Neurophysiol 71:2543-2547.

Hooper SL, Moulins M (1989) Switching of a neuron from one network to another by sensory-induced changes in membrane properties. Science 244:1587-1589.

Hooper SL, Moulins M (1990) Cellular and synaptic mechanisms responsible for a long lasting restructuring of the lobster pyloric network. J Neurophysiol 64:1574-1588. 
Hooper SL, Moulins M, Nonnotte L (1990) Sensory input induces long lasting changes in the output of the lobster pyloric network. J Neurophysiol 64:1555-1573.

Jenkins WM, Merzenich MM, Ochs MT, Allard T, Gui-Robles E (1990) Functional reorganization of primary somatosensory cortex in adult owl monkeys after behaviorally controlled tactile stimulation. J Neurophysiol 63:82-104.

Kandel ER, Schwartz JH (1982) Molecular biology of learning: modulation of transmitter release. Science 218:433-443.

Kleim JA, Barbay S, Nudo RJ (1998) Functional reorganization of the rat motor cortex following motor skill learning. J Neurophysiol 80:3321-3325

Lechner HA, Byrne JH (1998) New perspectives on classical conditioning: a synthesis of Hebbian and non-Hebbian mechanisms. Neuron 20:355-358.

Le Feuvre Y, Fénelon V, Meyrand P (1999) Central inputs mask multiple adult neural networks within a single embryonic network. Nature 402:660-664.

Lin XY, Glanzman DL (1994) Hebbian induction of long-term potentiation of Aplysia sensorimotor synapses: partial requirement for activation of an NMDA receptor. Proc R Soc Lond B Biol Sci 255:215-221.

Llinas R, Lopez-Barneo J (1988) Electrophysiology of mammalian tectal neurons in vitro. II. Long-term adaptation. J Neurophysiol 60:869-878.

Lockery SR, Sejnowski TJ (1993) A lower bound on the detectability of nonassociative learning in the local bending reflex of the medicinal leech. Behav Neural Biol 59:208-224.

Mackey SL, Kandel ER, Hawkins RD (1989) Identified serotonergic neurons LCB1 and RCB1 in the cerebral ganglia of Aplysia produce presynaptic facilitation of siphon sensory neurons. J Neurosci 9:4227-4235.

Magazanik LG, Vyskocil F (1970) Dependence of acetylcholine desensitization on the membrane potential of the frog muscle fiber and on the ionic changes in the medium. J Physiol (Lond) 210:507-518.

Magleby KL, Pallota BS (1981) A study of desensitization of acetylcholine receptors using nerve-released transmitter in the frog. J Physiol (Lond) 316:225-250.

Marder E, Calabrese RL (1996) Principles of rhythmic motor pattern generation. Physiol Rev 76:687-717.

Meyrand P, Simmers J, Moulins M (1991) Construction of a patterngenerating circuit with neurons of different networks. Nature 351:60-63.

Miller JP, Selverston AI (1979) Rapid killing of single neurons by irradiation of intracellular injected dye. Science 206:702-704.

Miller JP, Selverston AI (1982) Mechanisms underlying pattern generation in lobster stomatogastric ganglion as determined by selective inactivation of identified neurons II. Oscillatory properties of pyloric neurons. J Neurophysiol 48:1378-1391.

Moulins M, Vedel J-P (1977) Programmation centrale de l'activité motrice rythmique du tube digestif antérieur chez les crustacés décapodes. J Physiol (Paris) 73:471-510.

Nadler MA, Harrison LM, Stephen JA (2000) Acquisition of a new motor skill is accompanied by changes incutaneomuscular reflex responses recorded from finger muscles in man. Exp Brain Res 134:246-254

Nagy F, Dickinson PS (1983) Control of a central pattern generator by an identified modulatory interneuron in crustacea. I. Modulation of the pyloric motor output. J Exp Biol 105:33-58.

Nargeot R (2000) A cooperation of pre- and postsynaptic plasticity modifies the interaction between two neuronal networks. Soc Neurosci Abstr 26:454.

Nargeot R, Moulins M (1997) Sensory-induced plasticity of motor pattern selection in the lobster stomatogastric nervous system. Eur J Neurosci 9:1636-1645.

Nargeot R, Baxter DA, Byrne JH (1999a) In vitro analog of operant conditioning in Aplysia. I. Contingent reinforcement modifies the functional dynamics of an identified neuron. J Neurosci 19:2247-2260.

Nargeot R, Baxter DA, Byrne JH (1999b) In vitro analog of operant conditioning in Aplysia. II. Modifications of the functional dynamics of an identified neuron contribute to motor pattern selection. J Neurosci 19:2261-2272.

Parker D, Grillner S (2000) Activity-dependent plasticity of segmental and intersegmental synaptic connections in the lamprey spinal cord. Eur J Neurosci 12:2135-2146.

Pearson JC, Finkel LH, Edelman GM (1987) Plasticity in the organization of adult cerebral cortical maps: a computer simulation based on neuronal group selection. J Neurosci 7:4209-4223.

Pinsker HM, Kandel ER (1977) Short-term modulation of endogenous bursting rhythms by monosynaptic inhibition in Aplysia neurons: effects of contingent stimulation. Brain Res 125:51-64.

Plautz EJ, Milliken GW, Nudo RJ (2000) Effects of repetitive motor training on movement representations in adult squirrel monkeys: role of use versus learning. Neurobiol Learn Mem 74:27-55.

Rioult-Pedotti MS, Friedman D, Hess G, Donoghue JP (1998) Strengthening of horizontal cortical connections following skill learning. Nat Neurosci 3:230-234.

Rossignol S, Dubuc R (1994) Spinal pattern generation. Curr Opin Neurobiol 4:894-902.

Sanes JN (2000) Skill learning: motor cortex rules for learning and memory. Curr Biol 10:R495-R497.

Selverston AI, Miller JP (1980) Mechanisms underlying pattern generation in lobster stomatogastric ganglion as determined by selective inactivation of identified neurons. I. Pyloric system. J Neurophysiol 44:1102-1121.

Selverston AI, Moulins M (1987) The crustacean stomatogastric system: a model for the study of central nervous systems. Heidelberg: Springer.

Shashoua VE (1976) Brain metabolism and the acquisition of new behaviors. I. Evidence for specific changes in the pattern of protein synthesis. Brain Res 111:347-364.

Sherff C, Carew TJ (1999) Coincident induction of long-term facilitation in Aplysia: cooperativity between cell bodies and remote synapses. Science 17:1911-1914.

Sigvardt KA, Mulloney B (1982) Properties of synapses made by IVN command-interneurones in the stomatogastric ganglion of the spiny lobster Panulirus interruptus. J Exp Biol 97:153-168.

Singer W (1990) The formation of cooperative cell assemblies in the visual cortex. J Exp Biol 153:177-197.

Spencer GE, Naweed IS, Lukowiak K (1999) Neural changes after operant conditioning of the aerial respiratory behavior in Lymnaea stagnalis. J Neurosci 19:1836-1843.

Sporns O, Gally JA, Reeke GN, Edelman GM (1989) Reentrant signaling among simulated neuronal groups leads to coherency in their oscillatory activity. Proc Natl Acad Sci USA 86:7265-7269.

Staras K, Kemenes G, Benjamin PR (1999) Cellular traces of behavioral classical conditioning can be recorded at several specific sites in a simple nervous system. J Neurosci 19:347-357.

Takeyasu K, Udgaonkar JB, Hess GP (1983) Acetylcholine receptor: evidence for a voltage-dependent regulatory site for acetylcholine. Chemical kinetic measurements in membrane vesicles using a voltage clamp. Biochemistry 22:5973-5978.

Turrigiano GG, Nelson SB (2000) Hebb and homeostasis in neuronal plasticity. Curr Opin Neurobiol 10:358-364.

Turrigiano G, Abbott LF, Marder E (1994) Activity-dependent changes in the intrinsic properties of cultured neurons. Science 264:974-977.

Turrigiano GG, Leslie KR, Desai NS, Rutherford LC, Nelson SB (1998) Activity-dependent scaling of quantal amplitude in neocortical neurons. Nature 391:892-896.

Walters ET, Byrne JH (1983) Associative conditioning of single sensory neurons suggests a cellular mechanism for learning. Science 219:405-408.

Weimann JM, Marder E (1994) Switching neurons are integral members of multiple oscillatory networks. Curr Biol 4:896-902.

Wu J-Y, Cohen LB, Falk CX (1994) Neuronal activity during different behaviors in Aplysia: a distributed organization? Science 263:820-823.

Xu Y, Cleary LJ, Byrne JH (1994) Identification and characterization of pleural neurons that inhibit tail sensory neurons and motor neurons in Aplysia: correlation with FMRFamide immunoreactivity. J Neurosci 14:3565-3577. 